\title{
Expression of anti-apoptotic protein survivin in human endometrial carcinoma: Clinical and pathological associations as a separate factor and in combination with concomitant PTEN and p53 expression
}

\author{
AGGELIS STAVROPOULOS ${ }^{1}$, MICHAIL VARRAS $^{2}$, THIVI VASILAKAKI ${ }^{3}$, \\ VIKTORIA-KONSTANTINA VARRA ${ }^{4}$, FANI-NIKI VARRA ${ }^{5}$, AIKATERINI TSAVARI ${ }^{3}$, \\ APHRODITE NONNI $^{6}$, NIKOLAOS KAVANTZAS ${ }^{6}$ and ANDREAS C. LAZARIS ${ }^{6}$
}

\begin{abstract}
${ }^{1}$ Forth Obstetrics and Gynecology Department; ${ }^{2}$ Fifth Obstetrics and Gynecology Department, 'Elena Venizelou' General Hospital, Athens 11521; ${ }^{3}$ Department of Pathology, 'Tzaneio' General Hospital, Piraeus 18536; ${ }^{4}$ Department of Pharmacy, University of Patras, Patra 26504, Greece; ${ }^{5}$ Department of Pharmacy, Frederick University, Nicosia 1036, Cyprus;

${ }^{6}$ First Pathology Department, Medical School, National Kapodistrian University, Athens 11527, Greece
\end{abstract}

Received March 9, 2020; Accepted April 21, 2020

DOI: $10.3892 / \mathrm{ol} .2020 .11690$

\begin{abstract}
Endometrial carcinoma is one of the most common types of gynecological cancer. A total of 99 cases of primary endometrial carcinoma were investigated for survivin expression by immunohistochemistry. Furthermore, the association between concomitant survivin, PTEN and p53 expression, and clinicopathological parameters was examined. Immunopositivity for survivin was identified in $88 \%$ of cases. Concomitant survivin, PTEN and p53 expression (staining scores and intensity) was observed in $60 \%$ of endometrial adenocarcinomas. A significant association was identified between the sum of staining intensity and scores of survivin immunopositive cells, and patient age $(\mathrm{P}=0.028)$, histological grade $(\mathrm{P}<0.001)$, clinical stage $(\mathrm{P}=0.018)$ and fallopian tube and/or ovarian invasion $(\mathrm{P}=0.039)$. A negative tendency for correlation was observed between surivin and PTEN immunostaining scores $(\mathrm{P}=0.062 ; \rho=-0.238)$. Specimens with high scores of survivin expression tended to show decreased scores of PTEN immunostaining, and vice versa. However, in circumstances with an increased co-expression of survivin and PTEN, a statistically significant association with histological types was observed $(\mathrm{P}=0.020)$. A statistically significant positive correlation was identified between survivin and p53 sum co-expression $(\mathrm{P}=0.008 ; \rho=0.300)$. Furthermore, a significant
\end{abstract}

Correspondence to: Dr Michail Varras, Fifth Obstetrics and Gynecology Department, 'Elena Venizelou' General Hospital, Plateia Elenas Venizelou 2, Ampelokipoi, Athens 11521, Greece E-mail: mnvarras@otenet.gr

Key words: survivin, PTEN, p53, endometrial, carcinoma, immunohistochemistry, expression, concomitant, molecular pathology association was identified between survivin and p53 concomitant sum expression and age of patients $(\mathrm{P}=0.001)$, histological type $(\mathrm{P}=0.020)$, clinical stage $(\mathrm{P}=0.037)$, histological differentiation $(\mathrm{P}=0.001)$ and presence of fallopian tube and/or ovarian invasion $(\mathrm{P}=0.026)$. The present findings suggested that survivin may be an indicator of unfavorable outcome in older patients with endometrial carcinoma, in specific circumstances that are dependent on different concomitant genetic alterations and different combinations of molecular signaling pathways. Increased expression levels of survivin and PTEN may serve a role in the development of more aggressive endometrial carcinoma during their interaction. In addition, protein expression levels of survivin and p53 are positively correlated and may share a common molecular pathway to promote endometrial carcinogenesis. These findings provided evidence that survivin and p53 combined may be useful markers for the prediction of tumor behavior and prognosis.

\section{Introduction}

Endometrial carcinoma is one of the most common malignancies of the female genital tract in developed counties, with its life time risk estimated at 2-3\% $(1,2)$. Endometrial carcinomas are sporadic in $95 \%$ of cases, while $\leq 5 \%$ of cases is associated with a hereditary predisposition, especially when presenting in younger patients (3). Predisposing factors of the sporadic cases include hypertension, diabetes mellitus, late menopause, oestrogen replacement treatment and obesity. The most common symptom that leads to its diagnosis is postmenopausal vaginal bleeding. There are various histological subtypes of endometrial adenocarcinomas, including endometrioid, papillary serous and clear cell adenocarcinomas.

Endometrial carcinomas have been categorized into two major groups: Type I and type II carcinomas. The most common form of type I endometrial carcinoma is endometrioid adenocarcinoma, an oestrogen-dependent neoplasm 
that usually arises soon after menopause. Endometrioid adenocarcinomas also develop from endometrial hyperplasia in up to $80 \%$ of cases. The most common type II endometrial carcinoma is papillary serous adenocarcinoma, which is an oestrogen-independent neoplasm that develops in the atrophic endometrium, presents in elderly postmenopausal women and is associated with an aggressive behaviour and poor prognosis (3-8).

Endometrial cancer is successfully treated with hysterectomy and bilateral oophorectomy. Risk factors in dilation and curettage histological specimens include high-grade tumors or serous papillary or clear cell adenocarcinomas. Suggestive risk factors in MRI include tumor invasion greater than one-half of the myometrial thickness and/or involvement of pelvic lymph nodes. Therefore, when risk factors are present, then extensive surgery and postoperative radiotherapy are required. These patients might also benefit from new targeted therapies (9). Early-stage endometrial carcinomas result in favourable prognosis and excellent survival rates, with a 5-year overall survival of $75-90 \%$. However, women with more advanced or recurrent disease tend to have an extremely poor clinical outcome, with a 5-year survival rate of only 10-30\% (3-8).

Understanding the pathogenesis of endometrial carcinomas, particular at the molecular and cellular levels via the identification of genetic alterations, such as mutations, gene expression or dysregulation of apoptotic cell death, is essential for recognizing useful biomarkers for early tumor diagnosis and new therapies using target genes. An example of the involvement of apoptosis in carcinogenetic development is the permanent expression of survivin in various human malignancies by blocking the action of caspase- 3 and caspase-7, which are proteases and effectors of cell death (10-13). Survivin is a unique member of the inhibitor of the apoptosis protein family, which regulates the anti-apoptotic activity of the $\mathrm{v}$-Rel and nuclear factor- $\kappa B$ transcription factor families (13). It plays essential roles in mitosis, cellular stress response and inhibition of programmed cell death induced by both extrinsic and intrinsic apoptotic stimuli (14). The survivin protein is present in large amounts of fetal tissues and absent in most normal adult differentiated tissues (15). Survivin overexpression is linked to tumor progression, metastasis and increased rates of recurrence, treatment resistance and unfavorable prognosis in different types of cancer $(14,16-20)$. The survivin protein comprises 142 amino acids and has a molecular weight of $\sim 16.5 \mathrm{kD}(21)$. The gene encoding the survivin protein is BIRC5 which, in humans is located on chromosome 17q25 and encodes an mRNA that is divided into 4 exons and 3 introns (22). There are 5 different transcript isoforms of the human gene encoding survivin: survivin, survivin $2 \mathrm{~A}$, survivin $2 \mathrm{~B}$, survivin DEx 2 and survivin $3 \mathrm{~B}$ (23). Survivin is located in the nucleus, cytosol and mitochondria. In the nucleus, survivin shows its mitotic role. In response to apoptotic stimulus, survivin is transported from the mitochondria to the cytosol, where it exerts its anti-apoptotic potential (24). Survivin is regulated by a variety of oncogenes and tumor suppressor genes, including the phosphatidylinositol 3-kinase (PI3K)/mTOR pathway genes (14). The survivin and phosphatase and tensin homolog (PTEN) proteins are both thought to be inverse factors of apoptosis (25). Guha et al (26), found that the expression of tumor suppressor gene PTEN silences the expression of survivin in tumor cells, indepen- dently of the p53 pathway. In addition, Kim et al (27) reported that the inhibition of the PI3K/AKT pathway down-regulates survivin in neuroblastoma. Moreover, Sui et al (28) found that PTEN expression is negatively associated with survivin expression in the development and progression of ovarian cancer. In addition to all these findings, there has been evidence that the transcription of survivin is partially under the control of the $\mathrm{p} 53$ protein. Indeed, it has been found that wild-type p53 actively suppresses survivin expression (29-31). The findings of Kannangai et al (32), supported the role of p53 in regulating survivin expression by demonstrating an association between the abnormal nuclear accumulation of p53 and the overexpression of survivin in hepatocellular carcinomas, as determined by immunohistochemical analysis. Cohen et al (15), found that there was a significant positive correlation between nuclear survivin expression and mutant p53 in ovarian carcinoma. In a study published by the Polish Ovarian Cancer Group, the high nuclear expression of survivin was found to be a favorable predictor of progression-free survival and increased platinum sensitivity in patients with a positive p53 expression (33). In addition, Gąsowska-Bodnar et al (34) found that a high survivin expression could be a favorable prognostic factor in ovarian carcinomas, especially in the group of patients with a positive p53 expression. On the other hand, Gonzalez et al (35) found that high expression levels of survivin in combination with high expression levels of p53 were associated with an increased risk of local tumor progression in urothelial carcinomas of the bladder. These findings raise the question of whether there is a strong correlation between the concomitant protein expression of survivin, PTEN and p53 in endometrial carcinomas with remarkable clinical significance. However, the findings regarding endometrial carcinomas are not consistent so far in the international literature. Pallares et al (36), found that survivin expression was statistically significantly correlated with a decreased PTEN expression, while Erkanli et al (37) did not identify any such correlation.

Since the findings in the literature are conflicting with respect to the prognostic value of survivin expression in endometrial carcinomas, in the present study, immunohistochemical staining was performed to investigate the distribution of survivin expression in primary endometrial carcinomas from Greek patients who underwent surgery and the survivin protein expression levels were analyzed in association with well-established clinicopathological prognostic factors (16,36-42). Furthermore, in order to gain better insight into the synergistic function of survivin with tumor suppressor genes, the effects of PTEN and p53 expression, which had been previously evaluated by immunohistochemical analysis (43), were investigated on the expression of survivin in endometrial carcinomas. The main goal was to analyze the co-expression of survivin, PTEN and p53 using traditional clinicopathological prognostic factors and assess their prognostic value, as such evidence has still not been fully elucidated in the literature. Finally, in the current study, the frequencies of p53, PTEN and survivin were compared in women with normal, hyperplastic and carcinomatous endometria. An attempt was also made to determine the survivin expression differences between normal, hyperplastic and carcinomatous endometria when survivin was concomitantly expressed with PTEN or p53 in order to investigate the mechanisms of endometrial carcinogenesis. 


\section{Materials and methods}

Case selection. Tissue analysis was randomly performed on paraffin-embedded blocks of surgically resected tissues from 99 patients with primary endometrial carcinomas, who underwent surgery between 2006 and 2015, and had previously undergone evaluation for PTEN and p53 expression using immunohistochemical analysis (43). Samples were also obtained from 15 patients with normal endometria and 15 patients with endometrial hyperplasia. All patients included in this study at the time of data collection provided informed consent for the use of their data, as well as surgical specimens that remained following pathological diagnosis, in this study. The study was approved by The Ethical Committee of the Medical School of the Kapodistrian University of Athens, (Athens, Greece). The following histopathological parameters were determined: Histological type and grade, clinical stage, depth of myometrial invasion, lymph-vascular space invasion, fallopian tube and/or ovarian invasion, and presence of tumor necrosis.

Histological analysis and immunohistochemistry. For histological examination, endometrial carcinomas were routinely fixed with formalin and embedded in paraffin. Sections cut at a thickness of $\sim 4 \mu \mathrm{m}$, which included sufficient quantities of endometrial carcinoma mass, were mounted on silane-coated glass slides. Hematoxylin and eosin staining was performed.

Unstained slides containing endometrial carcinoma sections from each patient were used at the same time to investigate the immunohistochemical expression of p53, PTEN and survivin. For immunohistochemical analysis, sections of the formalin-fixed 5- $\mu \mathrm{m}$ thick sections were cut from the paraffin-embedded endometrial carcinoma specimens. The following primary antibodies were used: Monoclonal rabbit anti-survivin antibody (Cell Signaling Techology Inc.), mouse monoclonal anti-p53 antibody (clone DO-7; Thermo Fisher Scientific, Inc.) and monoclonal PTEN (clone MMAC; Novocastra). Deparaffinization, rehydration and epitope retrieval was performed using the PT link system (Agilent Technologies Inc.). The pretreatment Module buffer (100X citrate at $\mathrm{pH}$ 9.0) was used for $1 \mathrm{~h}$. The slides were rinsed in gently running followed by distilled water. The slides were immersed into $3.3 \% \mathrm{H}_{2} \mathrm{O}_{2}$ for $10 \mathrm{~min}$ in the dark, washed with tap water followed by distilled water and buffer, and incubated with the appropriate monoclonal antibody. Slides were washed extensively in buffer. Horseradish peroxidase-polymer secondary antibodies (Agilent Technologies, Inc.) were used for a 30-min incubation. 3',3'-Diaminobenzidine was used as a chromogen and the slides were incubated for $5 \mathrm{~min}$. The sections were counterstained in Meyer's hematoxylin, washed again and dehydrated with ethanol and xylene prior to mounting. The dilutions used for the primary antibodies were 1:200 for p53, 1:100 for PTEN and 1:400 for survivin.

No significant differences in immunoreactivity were identified when comparing sections from older paraffin blocks with others from recent blocks, suggesting that activated survivin immunoreactivity is well presented in paraffin-embedded tissues. The fraction of the positively stained tumor cells was scored following the examination of 20 high-power fields (magnification, $\mathrm{x} 400$ ) of endometrial adenocarcinomas. The scores for the immunohistochemical expression of survivin, p53 and PTEN were classified into the following 4 categories, according to the percentage of the positive staining area in relation to the whole carcinoma area: $0,<5 \%$ Immunopositive cells; $1,5-25 \%$ immunopositive cells (low scores); 2, 25-75\% immunopositive cells (moderate scores); $3, \geq 75 \%$ immunopositive cells (high scores). Cases with $\geq 5 \%$ positive endometrial carcinoma cells were defined as positive, and all other cases as negative.

The intensity of survivin staining in every stained slide was assessed as red-brown staining and classified into the following 4 categories: 0 , Absent; 1 , weak (faintly perceptible staining); 2 , moderate staining; 3 , strong staining (corresponded to staining intensity similar to that seen in positive control tissue sections).

In every stained slide, the scores of immunohistochemical expression of survivin, p53 and PTEN, and their staining intensity was then combined to produce the final sum of immunohistochemical expression, which was classified into the following 4 categories: -, (0); +, (1-2); ++, (3-4); +++, (5-6).

Since endometrial adenocarcinomas showed heterogeneous staining, the dominant pattern was used for scoring. Overall the exclusively nuclear localization of survivin protein was identified in all survivin-positive cases. The immunohistochemical staining for survivin is shown in Figs. 1 and 2. The slides were scored independently by 2 pathologists who were unaware of the clinicopathological data.

Statistical analysis. Categorical variables are presented as absolute (n) and relative (\%) frequencies, while continuous variables are presented as medians (min, max). Associations between categorical variables were assessed by exact Pearson's $\chi^{2}$ test. To investigate whether the median levels of a quantitative variable differed between 2 groups, the Mann-Whitney test was used, while for $\geq 3$ groups the Kruskal-Wallis was used (with Dunn test for post hoc analysis). Finally, to investigate correlations between 2 parameters, Spearman's correlation coefficient was used. Statistical significance was set at a two-tailed $\mathrm{P}<0.05$. Data were analyzed using IBM SPSS Statistics, v25.0 (IBM Corp.).

\section{Results}

Clinicopathological and immunohistochemical study of endometrioid, papillary serous and clear cell endometrial adenocarcinomas. The clinicopathological data of our study was previously described and reported (43). The specimens included 20 endometrioid endometrial carcinomas of histological grade 1 (G1), 47 of G2 and 19 of G3, as well as 13 papillary serous carcinomas or clear cell carcinomas. A total of 68 tumors were clinical stage I, 15 stage II and 5 stage III. The correlation between survivin immunohistological expression (score, intensity and sum of score and intensity) and clinicopathological parameters, such as tumor grade, clinical stage and depth of myometrial invasion was evaluated.

The survivin immunohistochemical expression scores were not statistically significant, as compared to the mean age of patients $(\mathrm{P}=0.121)$, depth of myometrial invasion $(\mathrm{P}=0.255)$, fallopian tube and/or ovarian invasion $(\mathrm{P}=0.073)$ and histological types $(\mathrm{P}=0.241$; Table I).

There was, however, a statistically significant correlation between clinical stage and immunohistochemical survivin 

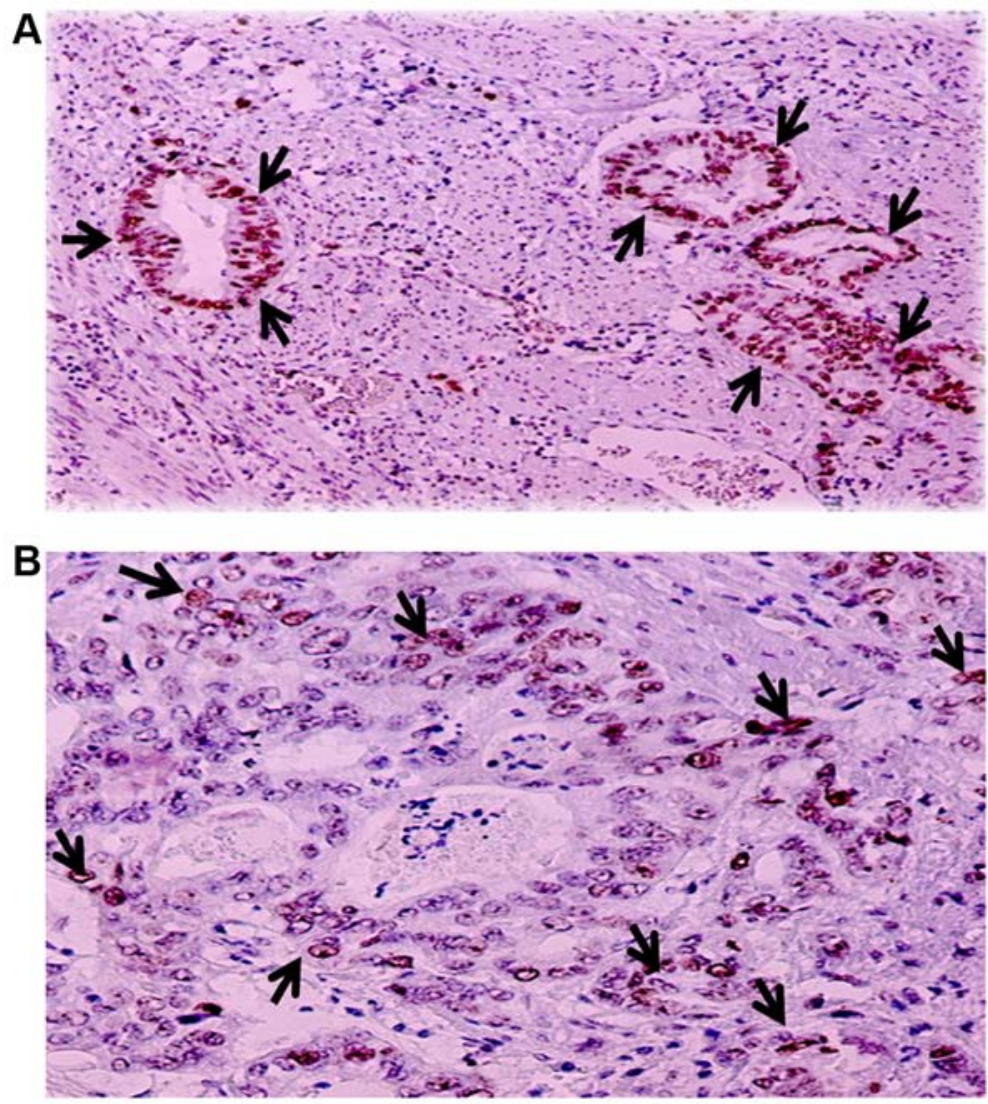

Figure 1. Positive multifocal nuclear immunohistochemical expression of survivin in endometrial carcinoma. (A) Strong positive staining intensity (arrows). Magnification, x100. (B) Moderate scores of immunopositive cells (arrows). Magnification, x200.

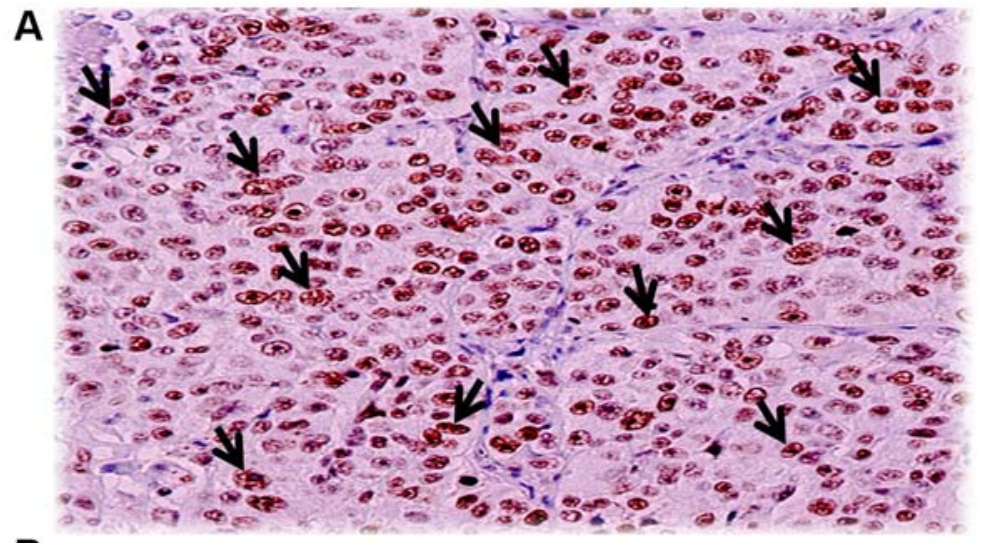

B

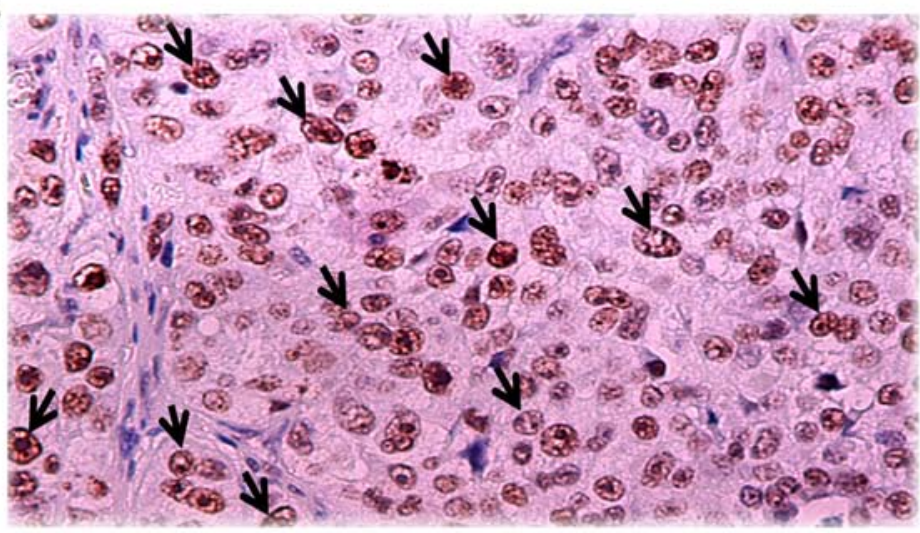

Figure 2. Positive multifocal nuclear immunohistochemical expression of survivin in endometrial carcinoma. (A) High scores of immunopositive cells (arrows). Magnification, x200. (B) Strong positive staining intensity and high scores of immunopositive cells (arrows). Magnification, x400. 


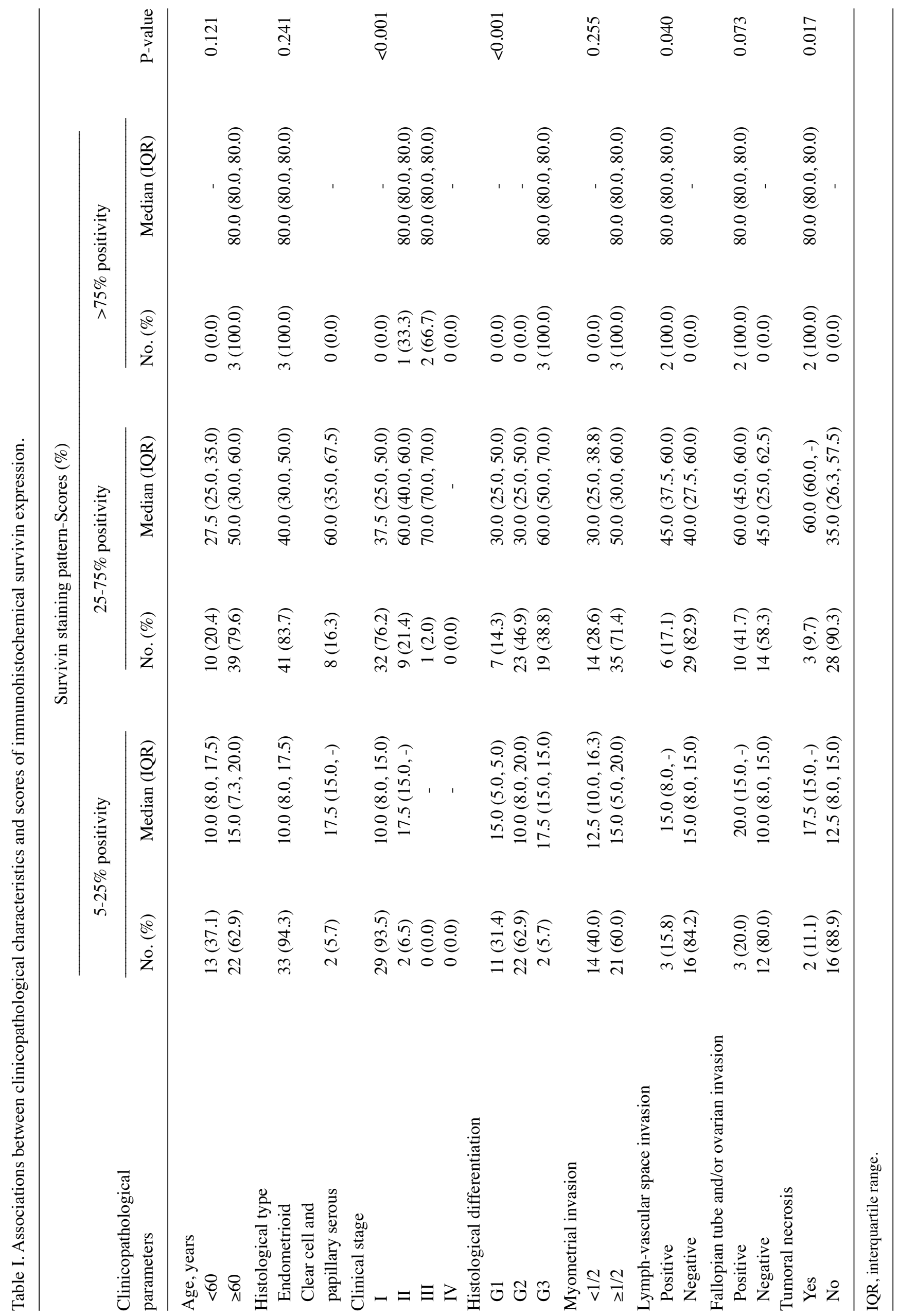



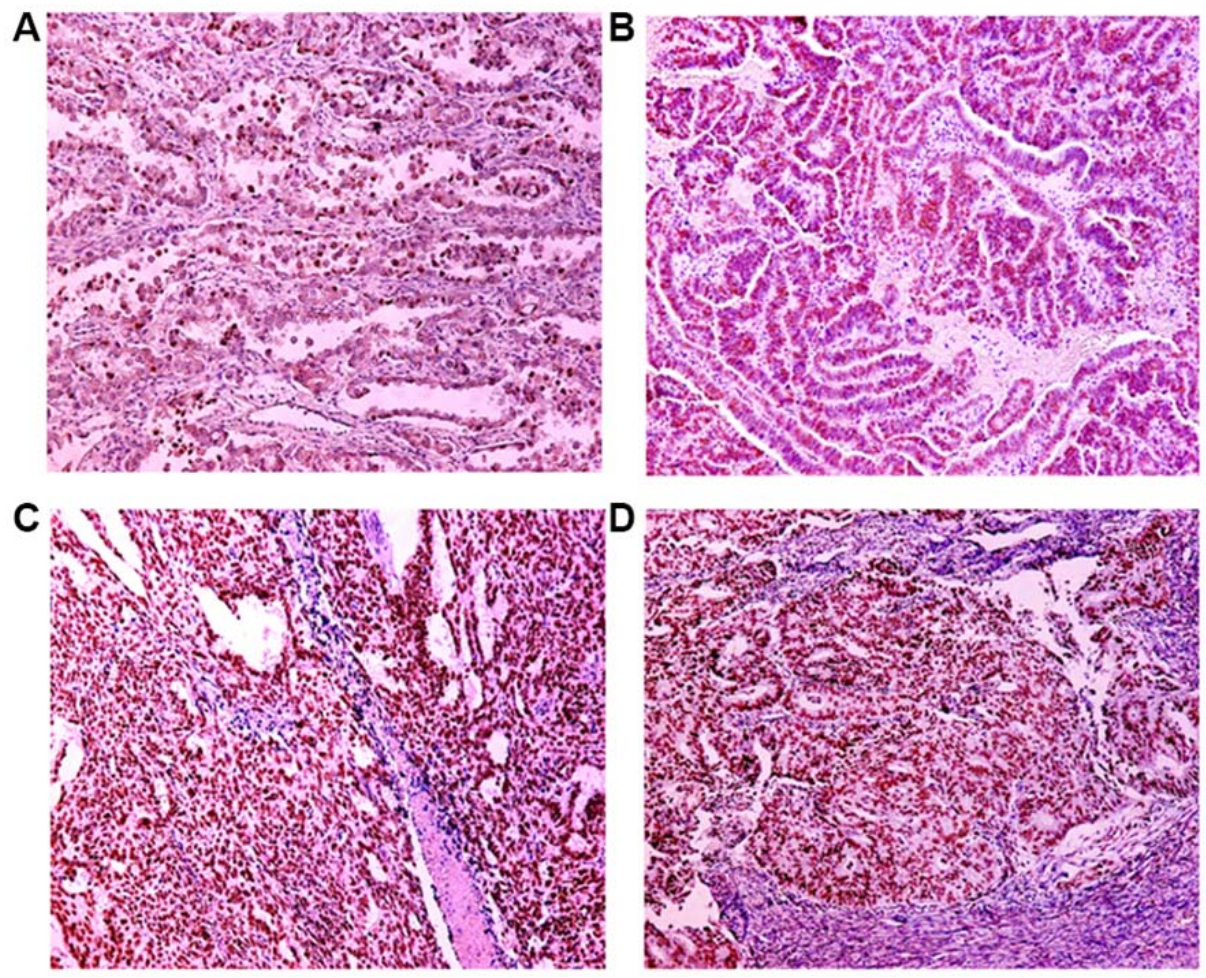

Figure 3. Immunohistochemical survivin expression in different clinical stages of endometrial carcinoma; (A) 30\% of immunopositive cells in clinical stage I; (B) $40 \%$ of immunopositive cells in clinical stage I; (C) $60 \%$ of immunopositive cells in clinical stage II; (D) $70 \%$ of immunopositive cells in clinical stage III. Original magnification, $\mathrm{x} 100$.
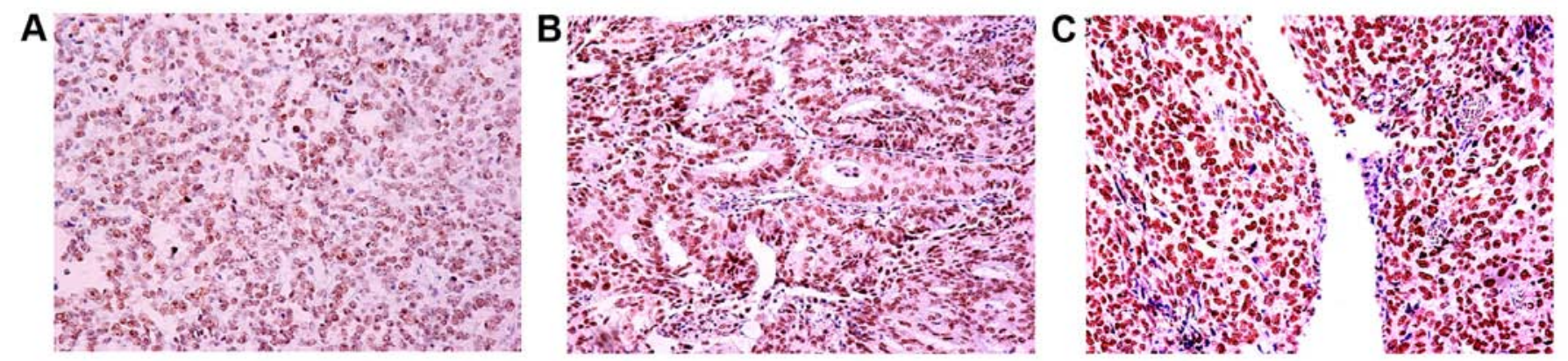

Figure 4. Moderate and high scores of survivin immunohistochemical expression. (A) Moderate expression, 60\%; (B) moderate expression, 70\%; and (C) high expression, $80 \%$. Original magnification, $\mathrm{x} 200$.

expression scores ( $\mathrm{P}<0.001$; Table I). Among those with a 5-25\% survivin staining pattern, 29 were classified as clinical stage I (93.5\%), and 2 as clinical stage II (6.5\%). Among those that exhibited a $25-75 \%$ survivin staining pattern, 32 were classified as clinical stage I (76.2\%), 9 as clinical stage II (21.4\%) and 1 as clinical stage III. Finally, among those with a survivin staining pattern of $>75 \%$, 1 was classified as clinical stage II (33.3\%) and 2 as clinical stage III (66.7\%). Earlier clinical stages were associated with lower survivin-positive immunostaining counts, while higher clinical stages were associated with medium/higher survivin-positive immunostaining counts. Fig. 3 shows the survivin immunohistochemical expression in different clinical stages of endometrial carcinomas, while Fig. 4 shows the moderate and high scores of survivin immunohistochemical expression.

There was a statistically significant correlation between histological grades and scores of immunohistochemical survivin expression $(\mathrm{P}<0.001$; Table I). Among those with a $5-25 \%$ survivin staining pattern, 11 were classified as G1 (31.4\%), 22 as G2 (6.5\%) and 2 as G3 (5.7\%). Among those with a $25-75 \%$ survivin staining pattern, 7 were classified as G1 (14.3\%), 23 as G2 (46.9\%) and 19 as G3 (38.8\%). Finally, all 3 patients with a survivin staining pattern $>75 \%$ were classified as G3 (100.0\%). Lower grade levels were associated with lower survivin-positive immunostaining counts than expected, while higher grade levels were associated with medium/higher survivin-positive immunostaining counts than expected.

Furthermore, there was a statistically significant correlation between lymph-vascular space invasion and scores of immunohistochemical survivin expression $(\mathrm{P}=0.040$; Table I). Among those with a 5-25\% survivin staining pattern, 3 had a lymph-vascular space invasion (15.8\%), while there was an absence of lymph-vascular space invasion in 16 patients 
Table II. Associations between clinicopathological characteristics and intensity of immunohistochemical survivin expression.

\begin{tabular}{|c|c|c|c|}
\hline \multirow[b]{2}{*}{ Clinicopathological parameters } & \multicolumn{2}{|c|}{ Survivin staining pattern-intensity (\%) } & \multirow[b]{2}{*}{ P-value } \\
\hline & Moderate, n (\%) & Strong, n $(\%)$ & \\
\hline \multicolumn{4}{|l|}{ Age, years } \\
\hline$<60$ & $16(36.4)$ & $7(16.3)$ & \multirow[t]{2}{*}{0.051} \\
\hline$\geq 60$ & $28(63.6)$ & $36(83.7)$ & \\
\hline \multicolumn{4}{|l|}{ Histological type } \\
\hline Endometrioid & $42(95.5)$ & $35(81.4)$ & \multirow[t]{2}{*}{0.049} \\
\hline Clear cell and papillary serous & $2(4.5)$ & $8(18.6)$ & \\
\hline \multicolumn{4}{|l|}{ Clinical stage } \\
\hline $\mathrm{I}$ & $36(92.3)$ & $25(67.6)$ & \multirow[t]{4}{*}{0.012} \\
\hline II & $3(7.7)$ & $9(24.3)$ & \\
\hline III & $0(0.0)$ & $3(8.1)$ & \\
\hline IV & $0(0.0)$ & $0(0.0)$ & \\
\hline \multicolumn{4}{|l|}{ Histological differentiation } \\
\hline G1 & $14(31.8)$ & $4(9.3)$ & \multirow[t]{3}{*}{0.001} \\
\hline G2 & $25(56.8)$ & $20(46.5)$ & \\
\hline G3 & $5(11.4)$ & $19(44.2)$ & \\
\hline \multicolumn{4}{|l|}{ Myometrial invasion } \\
\hline$<1 / 2$ & $21(47.7)$ & $7(16.3)$ & \multirow[t]{2}{*}{0.003} \\
\hline$\geq 1 / 2$ & $23(52.3)$ & $36(83.7)$ & \\
\hline \multicolumn{4}{|l|}{ Lymph-vascular space invasion } \\
\hline Positive & $0(0.0)$ & $11(33.3)$ & \multirow[t]{2}{*}{0.002} \\
\hline Negative & $23(100.0)$ & $22(66.7)$ & \\
\hline \multicolumn{4}{|c|}{ Fallopian tube and/or ovarian invasion } \\
\hline Positive & $3(18.7)$ & $12(48.0)$ & \multirow[t]{2}{*}{0.097} \\
\hline Negative & $13(81.3)$ & $13(52.0)$ & \\
\hline \multicolumn{4}{|l|}{ Tumoral necrosis } \\
\hline Yes & $1(4.3)$ & $6(21.4)$ & \multirow[t]{2}{*}{0.112} \\
\hline No & $22(95.7)$ & $22(78.6)$ & \\
\hline
\end{tabular}

(84.2\%). Among those with a 25-75\% survivin staining pattern, 6 exhibited lymph-vascular space invasion (17.1\%) and 29 did not $(82.9 \%)$. Finally, 2 cases with a $>75 \%$ surviving staining pattern exhibited lymph-vascular space invasion (100.0\%). The presence of lymph-vascular space invasion was associated with higher survivin positive immunostaining counts, while the absence of lymph-vascular space invasion was associated with medium/lower survivin-positive immunostaining counts than expected.

A statistically significant association was observed between the presence of tumor necrosis and immunohistochemical survivin expression scores $(\mathrm{P}=0.017$; Table I). Among those with a 5-25\% survivin staining pattern, 2 had tumor necrosis (11.1\%) and 16 did not (88.9\%). Among those with a $25-75 \%$ survivin staining pattern, tumor necrosis was present in 3 cases (9.7\%) and absent in 28 cases (90.3\%). Finally, tumor necrosis was absent in 2 cases with a $>75 \%$ survivin staining pattern (100.0\%). The presence of tumor necrosis was associated with higher survivin-positive immunostaining counts, while its absence was associated with medium/lower survivin-positive immunostaining counts.
Out of 99 cases, 43 (43.4\%) exhibited a strong survivin expression intensity and $44(44.4 \%)$ a moderate one. The survivin expression intensity was marginally associated with the patient's age $(\mathrm{P}=0.051$; Table II). Specifically, the patients with a strong survivin expression intensity had a median age of 65 years (range, 53-90), while those with a moderate survivin expression had a median age of 62 years (range 42-85).

The intensity of survivin expression was statistically significantly associated with the histological type of the endometrial carcinomas ( $\mathrm{P}=0.049$; Table II). A strong positive expression was observed in $35(81.4 \%)$ cases of endometrioid carcinomas and in $8(18.6 \%)$ cases of clear cell or papillary serous adenocarcinomas. The corresponding frequencies for moderate expression were $42(95.5 \%)$ and $2(4.5 \%)$ respectively.

In addition, survivin expression intensity was statistically significantly associated with histological grade $(\mathrm{P}=0.001$; Table II). Among cases with a strong positive expression, 4 (9.3\%) were histological G1, 20 (46.5\%) G2, and 19 (44.2\%) $\mathrm{G} 3$. The corresponding frequencies for moderate survivin expression were 14 (31.8\%), 25 (56.8\%) and 5 (11.4\%) respec- 
Table III. Associations between clinicopathological characteristics and sum of stain intensity and scores of survivin expression.

\begin{tabular}{|c|c|c|c|c|c|}
\hline \multirow[b]{2}{*}{ Characteristics } & \multirow[b]{2}{*}{ Cases, n (\%) } & \multicolumn{3}{|c|}{ IHC results for survivin, $\mathrm{n}(\%)$} & \multirow[b]{2}{*}{ P-value } \\
\hline & & + & ++ & +++ & \\
\hline \multicolumn{6}{|l|}{ Age, years } \\
\hline$<60$ & $23(26.4)$ & $6(33.3)$ & $13(38.2)$ & $4(11.4)$ & 0.028 \\
\hline$\geq 60$ & $64(73.6)$ & $12(66.7)$ & $21(61.8)$ & $31(88.6)$ & \\
\hline \multicolumn{6}{|l|}{ Histological type } \\
\hline Endometrioid & $77(88.5)$ & $17(94.4)$ & $32(94.1)$ & $28(80.0)$ & 0.141 \\
\hline Clear cell and papillary serous & $10(11.5)$ & $1(5.6)$ & $2(5.9)$ & $7(20.0)$ & \\
\hline \multicolumn{6}{|l|}{ Clinical stage } \\
\hline I & $61(80.3)$ & $15(100.0)$ & $27(87.1)$ & $19(63.3)$ & 0.018 \\
\hline II & $12(15.8)$ & $0(0.0)$ & $4(12.9)$ & $8(26.7)$ & \\
\hline III & $3(3.9)$ & $0(0.0)$ & $0(0.0)$ & $3(10.0)$ & \\
\hline \multicolumn{6}{|l|}{ Histological differentiation } \\
\hline G1 & $18(20.7)$ & $8(44.4)$ & $6(17.6)$ & $4(11.4)$ & $<0.001$ \\
\hline $\mathrm{G} 2$ & $45(51.7)$ & $10(55.6)$ & $22(64.7)$ & $13(37.1)$ & \\
\hline G3 & $24(27.6)$ & $0(0.0)$ & $6(17.6)$ & $18(51.4)$ & \\
\hline \multicolumn{6}{|l|}{ Myometrial invasion } \\
\hline$<1 / 2$ & $28(32.2)$ & $9(50.0)$ & $12(35.3)$ & $7(20.0)$ & 0.083 \\
\hline$\geq 1 / 2$ & $59(67.8)$ & $9(50.0)$ & $22(64.7)$ & $28(80.0)$ & \\
\hline \multicolumn{6}{|l|}{ Lymph-vascular space invasion } \\
\hline Positive & $11(19.6)$ & $0(0.0)$ & $3(14.3)$ & $8(30.8)$ & 0.107 \\
\hline Negative & $45(80.4)$ & $9(100.0)$ & $18(85.7)$ & $18(69.2)$ & \\
\hline \multicolumn{6}{|l|}{$\begin{array}{l}\text { Fallopian tube and/or ovarian } \\
\text { invasion }\end{array}$} \\
\hline Positive & $15(36.6)$ & $0(0.0)$ & $5(33.3)$ & $10(52.6)$ & 0.039 \\
\hline Negative & $26(63.4)$ & $7(100.0)$ & $10(66.7)$ & $9(47.4)$ & \\
\hline \multicolumn{6}{|l|}{ Tumoral necrosis } \\
\hline Yes & $7(13.7)$ & $0(0.0)$ & $2(10.0)$ & $5(22.7)$ & 0.240 \\
\hline No & $44(86.3)$ & $9(100.0)$ & $18(90.0)$ & $17(77.3)$ & \\
\hline
\end{tabular}

$\mathrm{P}<0.05$, statistically significant results; $0.05<\mathrm{P}<0.10$, suggestive results. IHC, immunohistochemistry.

tively. Lower grade levels were associated with a moderate survivin expression, while higher grade levels with a stronger survivin expression.

Moreover, the histological types of endometrial carcinomas and the intensity of survivin staining were statistically correlated $(\mathrm{P}=0.049$; Table II). In cases with a strong positive survivin expression, 35 cases had endometrioid carcinomas (81.4\%) and 8 had clear cell and papillary serous carcinomas (18.6\%). On the contrary, in cases with a moderate positive survivin expression, 42 had endometrioid carcinomas (95.5\%) and 2 had clear cell and papillary serous carcinomas (4.5\%). Endometrioid carcinomas were associated with a more moderate survivin expression, while clear cell and papillary serous endometrial carcinomas were associated with a stronger survivin expression.

In addition, the depth of myometrial invasion and survivin staining intensity were statistically correlated $(\mathrm{P}=0.003)$. Among the 43 cases with a strong survivin expression, 21 $(47.7 \%)$ had a depth of myometrial invasion of $<50 \%$ of the thickness of the myometrium, while $23(52.3 \%)$ had a depth of $\geq 50 \%$ of the myometrial thickness. Among the 44 cases with moderate staining, $7(16.3 \%)$ had a depth of myometrial invasion of $<50 \%$ of the myometrial thickness, while the other $36(83.7 \%)$ had a depth of myometrial invasion of $\geq 50 \%$ of the myometrial thickness. Moderate survivin expression intensity was associated with a lower myometrial invasion, while strong survivin intensity with a deeper myometrial invasion.

Moreover, clinical stage and survivin staining intensity were statistically significantly correlated $(\mathrm{P}=0.012$; Table II). Among the cases with a strong survivin expression, 25 were clinical stage I (67.6\%), 9 in stage II $(24.3 \%)$ and 3 in clinical stage III $(8.1 \%)$. The corresponding frequencies of moderate intensity were $36(92.3 \%), 3(7.7 \%)$ and $0(0.0 \%)$, respectively. Moderate survivin expression was associated with earlier clinical stages, while strong survivin expression with advanced clinical stages.

The lymph-vascular space invasion and the intensity of survivin staining were also statistically significantly correlated $(\mathrm{P}=0.002$; Table II). The 23 cases $(100.0 \%)$ with a moderate 

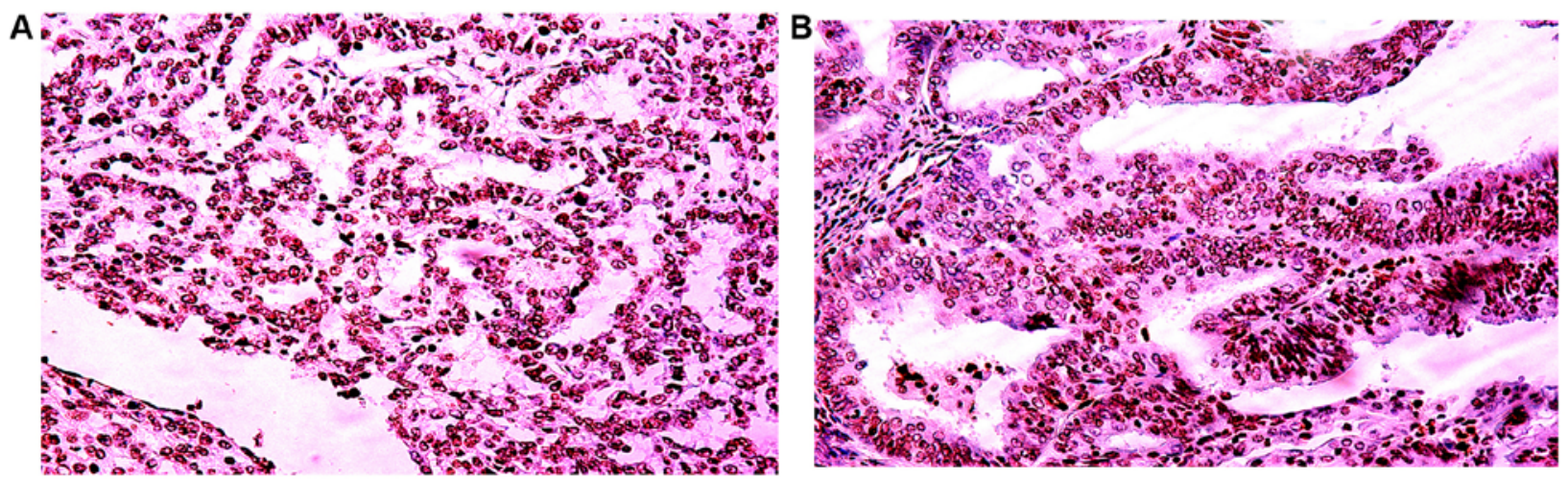

Figure 5. Positive immunohistochemical PTEN staining patterns in endometrial carcinoma. (A) Positive staining; (B) 25\%, low score. Original magnification, $\mathrm{x} 200$. PTEN, phosphatase and tensin homolog.
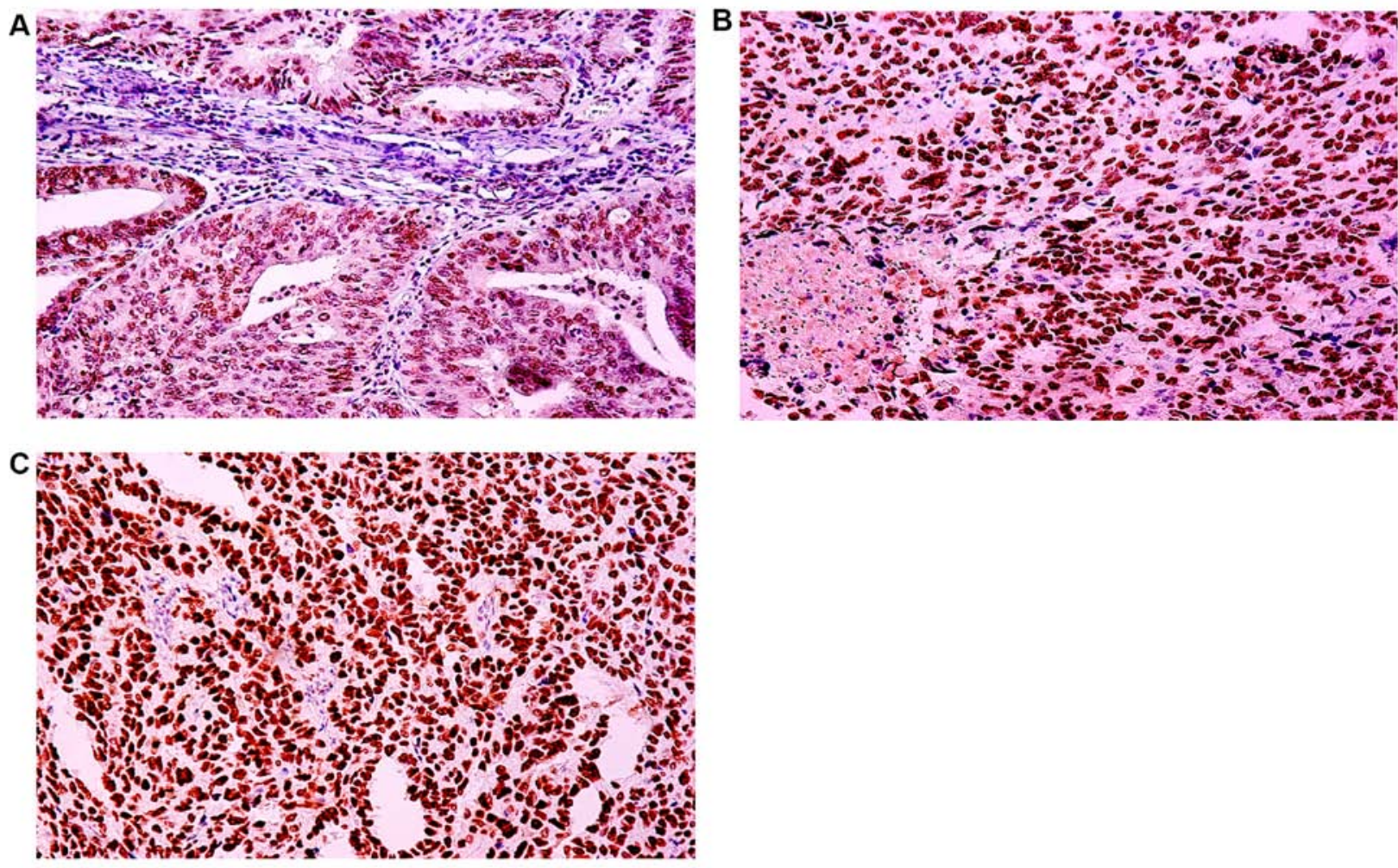

Figure 6. Positive immunohistochemical p53 staining patterns in endometrial carcinoma. (A) Moderate score, 30\%; (B) high score, 80\%; and (C) high score, $90 \%$. Original magnification, $\mathrm{x} 200$.

survivin staining intensity did not exhibit lymph-vascular space invasion. Among the cases with a strong survivin staining intensity, $22(66.7 \%)$ did not exhibit lymph-vascular space invasion, while the other 11 (33.3\%) did. Lymph-vascular space invasion was associated with strong survivin staining, while the absence of lymph-vascular space invasion with moderate survivin staining.

No statistically significant association was identified between survivin staining intensity and the presence of tumor necrosis $(\mathrm{P}=0.112)$ or fallopian tube and/or ovary invasion $(\mathrm{P}=0.097)$, although the results were suggestive of fallopian tube and/or ovary invasion (Table II).

Table III shows the sum of staining intensity and scores of survivin immunopositive cells in association with the clini- copathological characteristics. A significant association was observed between the sum of survivin positive cell scores and staining intensity, and patient age $(\mathrm{P}=0.028)$, histological grade $(\mathrm{P}<0.001)$, clinical stage $(\mathrm{P}=0.018)$ and presence of fallopian tube and/or ovarian invasion $(\mathrm{P}=0.039)$. No significant correlation was identified with histological type $(\mathrm{P}=0.141)$, depth of myometrial invasion $(\mathrm{P}=0.083)$, presence of lymph-vascular space invasion $(\mathrm{P}=0.107)$ or tumor necrosis $(\mathrm{P}=0.240)$.

Correlation between survivin expression and concomitant p53 or PTEN expression and clinicopathological parameters. This experiment utilized data from all the endometrial carcinomas of endometrioid, papillary serous and clear cell histological type. Immunopositivity for survivin was identified in $88 \%$ (87/99) of 

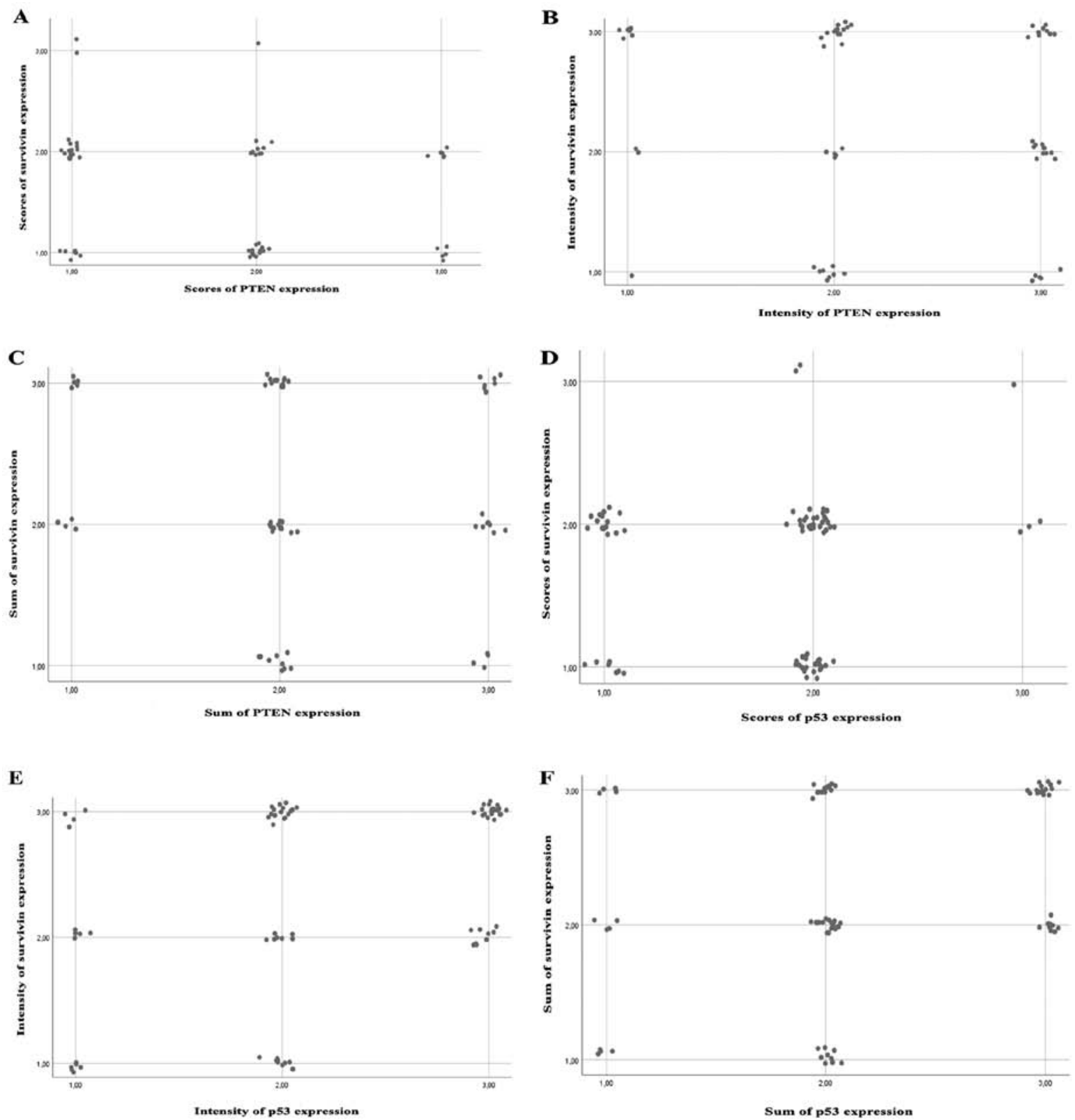

Figure 7. Scatterplot revealing the association between positive survivin immunostaining and PTEN or p53 co-expression. Scatterplot of the association between (A) positive immunostaining scores for survivin and PTEN expression, (B) staining intensity for survivin and PTEN expression, (C) the sum of staining intensity and scores of survivin and PTEN-positive cells, (D) positive immunostaining scores for survivin and p53 expression, (E) staining intensity for survivin and p53 expression, (F) sum of staining intensity and scores of survivin and p53-positive cells. The scatterplots were created with jittering of the position of the data points to avoid overplotting. PTEN, phosphatase and tensin homolog.

cases, according to the scores of immunopositive endometrial carcinoma cells, immunostaining intensity or the sum of positive cell scores and staining intensity; the same frequency was identified in all 3 staining categories. Our previous study described PTEN and p53 expression in endometrial adenocarcinomas from Greek patients (43). The overall rate of PTEN and p53 positivity was 77 and $89 \%$, respectively, according to the sum of staining intensity and positive cell scores. A survivin(-)/PTEN(+), survivin(-)/p53(+) or survivin (-)/PTEN(+)/p53(+) expression was identified in $6.1,6.1$ and $3.0 \%$ of patients respectively. A survivin(+)/PTEN(-), or survivin(+)/p53(-) or survivin $(+) /$ PTEN(-)/p53(-) expression was identified in 25.3, 10.1 and $28.3 \%$ of patients, respectively. Concurrent survivin, PTEN and p53 expression (scores and intensity) was found in $59(60 \%)$ endometrial adenocarcinomas, 56 which were endometrioid endometrial adenocarcinomas (95\%). Figs. 5 and 6 show the immunohistochemical staining patterns of PTEN and p53 in endometrial carcinomas, respectively.

The correlation between survivin and PTEN expression was investigated using Spearman's correlation coefficient. According to the proportion of immunopositive cell scores, there was a co-expression of survivin and PTEN in $25.8 \%$ of cases (16/62), as compared to $74.2 \%$ without such co-expression. The findings were not statistically significant $(\mathrm{P}=0.062$, $\rho=-0.238$ ), but they were suggestive for a correlation between the survivin and PTEN positive cell scores. The correlation between the positive cell scores of survivin and PTEN is presented in the scatterplot (Fig. 7A). Cases with high immu- 
Table IV. Co-expression of survivin and PTEN in endometrial carcinoma according to scores of immunopositive cells in relation to clinopathological parameters.

\begin{tabular}{|c|c|c|c|}
\hline Characteristics & $\begin{array}{c}\text { Patients with survivin } \\
\text { and PTEN low scores positive } \\
\text { expression, } \mathrm{n}(\%)\end{array}$ & $\begin{array}{c}\text { Patients with either } \\
\text { survivin or PTEN moderate scores } \\
\text { positive expression, } \mathrm{n}(\%)\end{array}$ & P-value \\
\hline \multicolumn{4}{|l|}{ Age, years } \\
\hline$<60$ & $4(57.1)$ & $17(25.4)$ & \multirow[t]{2}{*}{0.095} \\
\hline$\geq 60$ & $3(42.9)$ & $50(74.6)$ & \\
\hline \multicolumn{4}{|l|}{ Histological type } \\
\hline Endometrioid & $6(85.7)$ & $58(86.6)$ & \multirow[t]{2}{*}{$>0.999$} \\
\hline Clear cell and papillary serous & $1(14.3)$ & $9(13.4)$ & \\
\hline \multicolumn{4}{|l|}{ Clinical stage } \\
\hline $\mathrm{I}$ & $7(100.0)$ & $46(79.3)$ & \multirow[t]{3}{*}{0.444} \\
\hline II & $0(0.0)$ & $9(15.5)$ & \\
\hline III & $0(0.0)$ & $3(5.2)$ & \\
\hline \multicolumn{4}{|l|}{ Histological differentiation } \\
\hline G1 & $0(0.0)$ & $13(19.4)$ & \multirow[t]{3}{*}{0.143} \\
\hline $\mathrm{G} 2$ & $6(85.7)$ & $32(47.8)$ & \\
\hline G3 & $1(14.3)$ & $22(32.8)$ & \\
\hline \multicolumn{4}{|l|}{ Myometrial invasion } \\
\hline$<1 / 2$ & $1(14.3)$ & $22(32.8)$ & \multirow[t]{2}{*}{0.424} \\
\hline$\geq 1 / 2$ & $6(85.7)$ & $45(67.2)$ & \\
\hline \multicolumn{4}{|l|}{ Lymph-vascular space invasion } \\
\hline Yes & $3(50.0)$ & $8(18.6)$ & \multirow[t]{2}{*}{0.117} \\
\hline No & $3(50.0)$ & $35(81.4)$ & \\
\hline \multicolumn{4}{|c|}{ Fallopian tube and/or ovarian invasion } \\
\hline Yes & $0(0.0)$ & $11(35.5)$ & \multirow[t]{2}{*}{0.285} \\
\hline No & $4(100.0)$ & $20(64.5)$ & \\
\hline \multicolumn{4}{|l|}{ Tumoral necrosis } \\
\hline Yes & $1(20.0)$ & $4(10.5)$ & \multirow[t]{2}{*}{$>0.999$} \\
\hline No & $4(80.0)$ & $34(89.5)$ & \\
\hline
\end{tabular}

PTEN, phosphatase and tensin homolog.

nopositive survivin scores tended to have low scores of PTEN immunostaining.

According to the intensity of staining there was a coexistence of survivin and PTEN expression in $23.8 \%$ of cases (15/63), as compared to $76.2 \%$ without such co-expression. The findings were not statistically significant $(\mathrm{P}=0.119, \rho=-0.198)$. The correlation between the intensity of survivin and PTEN immunopositivity is presented in the scatterplot (Fig. 7B).

According to the sum of staining and positive cell scores, there was a coexistence of survivin and PTEN expression in $32.3 \%$ of cases (20/62), as compared to $67.7 \%$ without such co-expression. The findings were not statistically significant $(\mathrm{P}=0.399, \rho=-0.109)$. The correlation between the sum of survivin and PTEN immunopositivity is presented in the scatterplot (Fig. 7C).

In addition, the correlation between survivin and p53 expression was investigated using Spearman's rank correlation. According to the proportion of immunopositive cell scores there was a coexistence of survivin and p53 expression in $46.8 \%$ of cases (36/77), as compared to $53.2 \%$ without such co-expression. The findings were not statistically significant $(\mathrm{P}=0.442$, $\rho=0.089$ ). The correlation between the scores of survivin and p53 immunopositivity is presented in the scatterplot (Fig. 7D).

According to the intensity of staining there was a co-expression of survivin and p53 in $42.3 \%$ of cases (33/78), as compared to $57.7 \%$ without such co-expression. The findings were statistically significant $(\mathrm{P}=0.001, \rho=0.372)$ and the correlation between survivin and $\mathrm{p} 53$ staining intensity is presented in the scatterplot (Fig. 7E). According to the sum of staining intensity and positive cell scores, there was a co-expression of survivin and p53 in $46.8 \%$ of cases (36/77), as compared to $53.2 \%$ without such co-expression. The findings were statistically significant $(\mathrm{P}=0.008, \rho=0.300)$ and the correlation between survivin and p53 sum immunopositivity is presented in the scatterplot (Fig. 7F). Therefore, the increase in the intensity or sum (intensity and scores) of survivin expression was associated with an increase in the intensity or sum (intensity and scores) of the p53 expression. 
Table V. Co-expression of survivin and PTEN in endometrial carcinomas according to stain intensity of immunopositive cells in relation to clinopathological parameters.

\begin{tabular}{|c|c|c|c|c|}
\hline Characteristics & $\begin{array}{l}\text { Patients with survivin } \\
\text { and PTEN weak positive } \\
\text { expression, n }(\%)\end{array}$ & $\begin{array}{l}\text { Patients with either } \\
\text { survivin or PTEN moderate } \\
\text { positive expression, } \mathrm{n}(\%)\end{array}$ & $\begin{array}{l}\text { Patients with survivin } \\
\text { and PTEN strong positive } \\
\text { expression, } \mathrm{n}(\%)\end{array}$ & P-value \\
\hline \multicolumn{5}{|l|}{ Age, years } \\
\hline$<60$ & $1(9.1)$ & $15(32.6)$ & $1(33.3)$ & 0.145 \\
\hline$\geq 60$ & $10(90.9)$ & $31(67.4)$ & $2(66.7)$ & \\
\hline \multicolumn{5}{|l|}{ Histological type } \\
\hline Endometrioid & $9(81.8)$ & $44(95.7)$ & $2(66.7)$ & 0.098 \\
\hline Clear cell and papillary serous & $2(18.2)$ & $2(4.3)$ & $1(33.3)$ & \\
\hline \multicolumn{5}{|l|}{ Clinical stage } \\
\hline I & $8(88.9)$ & $34(82.9)$ & $3(100.0)$ & 0.366 \\
\hline II & $1(11.1)$ & $4(9.8)$ & $0(0.0)$ & \\
\hline III & $0(0.0)$ & $3(7.3)$ & $0(0.0)$ & \\
\hline \multicolumn{5}{|l|}{ Histological differentiation } \\
\hline G1 & $6(54.5)$ & $11(23.9)$ & $0(0.0)$ & 0.023 \\
\hline $\mathrm{G} 2$ & $3(27.3)$ & $24(52.2)$ & $2(66.7)$ & \\
\hline G3 & $2(18.2)$ & $11(23.9)$ & $1(33.3)$ & \\
\hline \multicolumn{5}{|l|}{ Myometrial invasion } \\
\hline$<1 / 2$ & $5(45.5)$ & $17(37.0)$ & $0(0.0)$ & 0.479 \\
\hline$\geq 1 / 2$ & $6(54.5)$ & $29(63.0)$ & $3(100.0)$ & \\
\hline \multicolumn{5}{|l|}{ Lymph-vascular space invasion } \\
\hline Yes & $0(0.0)$ & $4(14.3)$ & $2(100.0)$ & 0.007 \\
\hline No & $9(100.0)$ & $24(85.7)$ & $0(0.0)$ & \\
\hline \multicolumn{5}{|l|}{$\begin{array}{l}\text { Fallopian tube and/or ovarian } \\
\text { invasion }\end{array}$} \\
\hline Yes & $1(16.7)$ & $6(28.6)$ & $0(0.0)$ & 0.031 \\
\hline No & $5(83.3)$ & $15(71.4)$ & $0(0.0)$ & \\
\hline \multicolumn{5}{|l|}{ Tumoral necrosis } \\
\hline Yes & $0(0.0)$ & $4(15.4)$ & $0(0.0)$ & 0.516 \\
\hline No & $9(100.0)$ & $22(84.6)$ & $0(0.0)$ & \\
\hline
\end{tabular}

$\mathrm{P}<0.05$, statistically significant results; $0.05<\mathrm{P}<0.10$, suggestive results. PTEN, phosphatase and tensin homolog.

Tables IV-IX present the co-expression of survivin with PTEN or p53 immunopositivity in relation to clinicopathological factors in endometrial carcinomas. There was a statistically significant correlation between the co-expression of survivin and PTEN in endometrial carcinomas, according to staining intensity and histologic grade $(\mathrm{P}=0.023)$, lymph-vascular space involvement $(\mathrm{P}=0.007)$ and presence of fallopian tube and/or ovarian invasion $(\mathrm{P}=0.031$; Table $\mathrm{V})$. Furthermore, there was a statistically significant correlation between the sum of staining intensity and immunopositive cell scores, and the histological type $(\mathrm{P}=0.020$; Table VI).

In the case of concomitant survivin and p53 expression, there was a statistically significant correlation between the positive cell scores and the patient's age $(\mathrm{P}=0.001)$, and the presence of fallopian tube and/or ovarian invasion $(\mathrm{P}=0.027$; Table VII). The staining intensity was correlated with patient age $(\mathrm{P}=0.014)$, histological type $(\mathrm{P}=0.001)$, clinical stage $(\mathrm{P}=0.032)$ and histological differentiation $(\mathrm{P}<0.001$; Table VIII). The sum of immunopositive cell-scores and staining -intensity was correlated with patient age $(\mathrm{P}=0.001)$, histological type $(\mathrm{P}=0.020)$, clinical stage $(\mathrm{P}=0.037)$, histological differentiation $(\mathrm{P}=0.001)$ and presence of fallopian tube and/or ovarian invasion ( $\mathrm{P}=0.026$; Table IX).

Comparison of the immunohistochemical expression of p53, PTEN and survivin among normal, hyperplastic and carcinomatous endometria. Fig. 8 shows the p53 immunohistochemical expression in normal and hyperplastic endometria (Fig. 8A and B) and absence of p53 expression in a normal endometrium (Fig. 8C). Therefore, in the case of p53 expression, the staining scores were statistically significantly correlated between normal and hyperplastic endometria $(\mathrm{P}=0.035)$; patients with endometrial hyperplasia showed an increased count of high p53 expression scores, while patients with normal endometria showed an increased count of low or moderate p53 scores (Fig. 9A). In addition, the scores of p53 expression were statistically significantly correlated between 
Table VI. Co-expression of survivin and PTEN in endometrial carcinomas according to sum of stain intensity and scores of immunopositive cells in relation to clinopathological parameters.

\begin{tabular}{|c|c|c|c|}
\hline Characteristics & $\begin{array}{l}\text { Patients with either } \\
\text { survivin or PTEN ++ } \\
\text { expression, } \mathrm{n}(\%)\end{array}$ & $\begin{array}{c}\text { Patients with survivin } \\
\text { and PTEN +++ expression, } \\
\mathrm{n}(\%)\end{array}$ & P-value \\
\hline \multicolumn{4}{|l|}{ Age, years } \\
\hline$<60$ & $17(29.8)$ & $1(50.0)$ & \multirow[t]{2}{*}{0.101} \\
\hline$\geq 60$ & $40(70.2)$ & $1(50.0)$ & \\
\hline \multicolumn{4}{|l|}{ Histological type } \\
\hline Endometrioid & $54(94.7)$ & $1(50.0)$ & \multirow[t]{2}{*}{0.020} \\
\hline Clear cell and papillary serous & $3(5.3)$ & $1(50.0)$ & \\
\hline \multicolumn{4}{|l|}{ Clinical stage } \\
\hline I & $40(80.0)$ & $2(100.0)$ & \multirow[t]{3}{*}{0.837} \\
\hline II & $7(14.0)$ & $0(0.0)$ & \\
\hline III & $3(6.0)$ & $0(0.0)$ & \\
\hline \multicolumn{4}{|l|}{ Histological differentiation } \\
\hline G1 & $12(21.1)$ & $0(0.0)$ & \multirow[t]{3}{*}{0.363} \\
\hline $\mathrm{G} 2$ & $32(56.1)$ & $1(50.0)$ & \\
\hline G3 & $13(22.8)$ & $1(50.0)$ & \\
\hline \multicolumn{4}{|l|}{ Myometrial invasion } \\
\hline$<1 / 2$ & $18(31.6)$ & $0(0.0)$ & \multirow[t]{2}{*}{0.425} \\
\hline$\geq 1 / 2$ & $39(68.4)$ & $2(100.0)$ & \\
\hline \multicolumn{4}{|l|}{ Lymph-vascular space invasion } \\
\hline Yes & $8(21.6)$ & $1(50.0)$ & \multirow[t]{2}{*}{0.272} \\
\hline No & $29(78.4)$ & $1(50.0)$ & \\
\hline \multicolumn{4}{|c|}{ Fallopian tube and/or ovarian invasion } \\
\hline Yes & $10(34.5)$ & $0(0.0)$ & \multirow[t]{2}{*}{0.352} \\
\hline No & $19(65.5)$ & $0(0.0)$ & \\
\hline \multicolumn{4}{|l|}{ Tumoral necrosis } \\
\hline Yes & $5(14.7)$ & $0(0.0)$ & \multirow[t]{2}{*}{0.687} \\
\hline No & $29(85.3)$ & $0(0.0)$ & \\
\hline
\end{tabular}

$\mathrm{P}<0.05$, statistically significant results; $0.05<\mathrm{P}<0.10$, suggestive results. $\mathrm{PTEN}$, phosphatase and tensin homolog.

normal endometria and endometrial carcinomas $(\mathrm{P}=0.016)$; patients with endometrial carcinomas exhibited more 553 positive cell scores than those with normal endometria (Fig. 9B).

Fig. 10 shows the PTEN immunohistochemical expression in normal and hyperplastic endometria (Fig. 10A and B) and absence of PTEN expression in a normal endometrium(Fig. 10C). Therefore, in the case of PTEN expression, there was a statistical significance in the staining intensity of immunopositive cells between normal endometria and endometrial carcinomas $(\mathrm{P}<0.001)$; more patients with endometrial carcinomas exhibited weak or moderate or high PTEN expression intensity, as compared to those with normal endometria (Fig. 11A). In addition, there was a statistically significant association between the sum of staining intensity and PTEN immunopositive cell scores in normal endometria and endometrial carcinomas $(\mathrm{P}=0.002)$; patients with normal endometria showed a lower count of $(++)$ sum of PTEN positive expression, as compared to those with endometrial carcinomas (Fig. 11B). The intensity of PTEN expression was statistically significantly correlated between endometrial hyperplasias and carcinomas $(\mathrm{P}=0.002)$; patients with endometrial hyperplasia exhibited lower counts of moderate and strong PTEN expression than those with endometrial carcinomas (Fig. 11C). Finally, there was a statistically significant correlation in the sum of staining intensity and positive PTEN cell scores between endometrial hyperplasias and endometrial carcinomas ( $\mathrm{P}=0.006)$; patients with endometrial hyperplasia exhibited lower counts of $(+)$ and $(++)$ expression, as compared to those with endometrial carcinomas (Fig. 11D).

Fig. 12 shows the immunohistochemical expression of survivin in normal and hyperplastic endometria (Fig. 12A-C) and absence of survivin expression in a normal endometrium (Fig. 12D). In the case of concomitant expression of survivin and p53, according to the proportion of immunopositive cell scores, there was a statistically significant expression of survivin between normal endometria and endometrial carcinomas $(\mathrm{P}=0.048)$; patients with endometrial carcinomas demonstrated increased concurrent positive survivin and p53 cell scores as compared to those with a normal endometrium (Fig. 13A). In the 
Table VII. Co-expression of survivin and p53 in endometrial carcinoma according to scores of immunopositive cells in relation to clinicopathological parameters.

\begin{tabular}{|c|c|c|c|}
\hline Characteristics & $\begin{array}{l}\text { Patients with survivin } \\
\text { and p53 low scores } \\
\text { positive expression, n }(\%)\end{array}$ & $\begin{array}{l}\text { Patients with either } \\
\text { survivin or p53 moderate scores } \\
\text { positive expression, } \mathrm{n}(\%)\end{array}$ & P-value \\
\hline \multicolumn{4}{|l|}{ Age, years } \\
\hline$<60$ & $5(71.4)$ & $18(23.7)$ & \multirow[t]{2}{*}{0.001} \\
\hline$\geq 60$ & $2(28.6)$ & $58(76.3)$ & \\
\hline \multicolumn{4}{|l|}{ Histological type } \\
\hline Endometrioid & $7(100.0)$ & $65(85.5)$ & \multirow[t]{2}{*}{0.676} \\
\hline Clear cell and papillary serous & $0(0.0)$ & $11(14.5)$ & \\
\hline \multicolumn{4}{|l|}{ Clinical stage } \\
\hline I & $6(100.0)$ & $52(78.8)$ & \multirow[t]{3}{*}{0.320} \\
\hline II & $0(0.0)$ & $10(15.2)$ & \\
\hline III & $0(0.0)$ & $4(6.1)$ & \\
\hline \multicolumn{4}{|l|}{ Histological differentiation } \\
\hline G1 & $3(42.9)$ & $13(17.1)$ & \multirow[t]{3}{*}{0.315} \\
\hline $\mathrm{G} 2$ & $4(57.1)$ & $38(50.0)$ & \\
\hline G3 & $0(0.0)$ & $25(32.9)$ & \\
\hline \multicolumn{4}{|l|}{ Myometrial invasion } \\
\hline$<1 / 2$ & $2(28.6)$ & $27(35.5)$ & \multirow[t]{2}{*}{0.933} \\
\hline$\geq 1 / 2$ & $5(71.4)$ & $49(64.5)$ & \\
\hline \multicolumn{4}{|l|}{ Lymph-vascular space invasion } \\
\hline Yes & $0(0.0)$ & $11(22.0)$ & \multirow[t]{2}{*}{0.667} \\
\hline No & $4(100.0)$ & $39(51.3)$ & \\
\hline \multicolumn{4}{|c|}{ Fallopian tube and/or ovarian invasion } \\
\hline Yes & $0(0.0)$ & $14(37.8)$ & \multirow[t]{2}{*}{0.027} \\
\hline No & $3(100.0)$ & $23(62.2)$ & \\
\hline \multicolumn{4}{|l|}{ Tumoral necrosis } \\
\hline Yes & $0(0.0)$ & $5(11.1)$ & \multirow[t]{2}{*}{0.618} \\
\hline No & $4(100.0)$ & $40(88.9)$ & \\
\hline
\end{tabular}

$\mathrm{P}<0.05$, statistically significant results; $0.05<\mathrm{P}<0.10$, suggestive results.

case of concomitant survivin and PTEN expression, according to the intensity of immunopositivity, there was a statistically significant expression of survivin between endometrial hyperplasias and endometrial carcinomas $(\mathrm{P}=0.008)$; patients with endometrial carcinomas showed more weak or moderate intensity for concurrent positive survivin and PTEN immunostaining, as compared to those with endometrial hyperplasias (Fig. 13B). In addition, there was a statistically significant correlation in the sum of staining scores and intensity in the case of survivin and PTEN coexistence between endometrial hyperplasias and endometrial carcinomas $(\mathrm{P}=0.016)$; patients with endometrial carcinomas had an increased count of $(+)$ or $(++)$ sum expression for concurrent survivin and PTEN expression, as compared to patients with endometrial hyperplasias.

\section{Discussion}

In the present study, the immunohistochemical expression of survivin was examined in 99 endometrial adenocarcinomas from Greek patients. Survivin expression was observed in $88 \%(87 / 99)$ of cases, taking into account the overall histological types and confirming that survivin is a very common genetic alteration in endometrial carcinomas. In the international literature the distribution of survivin expression in endometrial carcinomas was $43-100 \%(36,38,40,44,45)$. Lambropoulou et at (38), also studied the expression of survivin in Greek patients with endometrial carcinomas and found a frequency of only $43 \%$. Brunner et al (40), identified the expression of survivin in $45 \%$ of cases, Pallares et al (36) in $76 \%$, Chuwa et al (45) in $86 \%$ and Lehner et al (44) in $100 \%$. These wide variations in the frequency of survivin expression in endometrial carcinomas could be due to a number of reasons, including geographic location, antibodies used, antibody dilutions, interpretation of staining, heterogeneity of endometrial carcinomas and differences in the immunohistochemichal protocols.

In the endometrium, survivin is not exclusively expressed in carcinomas and is therefore not a specific marker for 
Table VIII. Co-expression of survivin and p53 in endometrial carcinoma according to stain intensity of immunopositive cells in relation to clinicopathological parameters.

\begin{tabular}{|c|c|c|c|c|}
\hline Characteristics & $\begin{array}{l}\text { Patients with survivin } \\
\text { and p53 weak positive } \\
\text { expression, n }(\%)\end{array}$ & $\begin{array}{c}\text { Patients with either } \\
\text { survivin or p53 moderate } \\
\text { positive expression, n (\%) }\end{array}$ & $\begin{array}{l}\text { Patients with survivin } \\
\text { and p53 strong positive } \\
\text { expression, n }(\%)\end{array}$ & P-value \\
\hline \multicolumn{5}{|l|}{ Age, years } \\
\hline$<60$ & $3(23.1)$ & $18(35.3)$ & $0(0.0)$ & 0.014 \\
\hline$\geq 60$ & $10(76.9)$ & $33(64.7)$ & $8(100.0)$ & \\
\hline \multicolumn{5}{|l|}{ Histological type } \\
\hline Endometrioid & $12(92.3)$ & $50(98.0)$ & $6(75.0)$ & 0.001 \\
\hline $\begin{array}{l}\text { Clear cell and papillary } \\
\text { serous }\end{array}$ & $1(7.7)$ & $1(2.0)$ & $2(25.0)$ & \\
\hline \multicolumn{5}{|l|}{ Clinical stage } \\
\hline I & $10(90.9)$ & $41(87.2)$ & $2(33.3)$ & 0.032 \\
\hline II & $1(9.1)$ & $5(10.6)$ & $3(50.0)$ & \\
\hline III & $0(0.0)$ & $1(2.1)$ & $1(16.7)$ & \\
\hline \multicolumn{5}{|l|}{ Histological differentiation } \\
\hline G1 & $6(46.2)$ & $10(19.6)$ & $1(12.5)$ & $<0.001$ \\
\hline G2 & $7(53.8)$ & $31(60.8)$ & $2(25.0)$ & \\
\hline G3 & $0(0.0)$ & $10(19.6)$ & $5(62.5)$ & \\
\hline \multicolumn{5}{|l|}{ Myometrial invasion } \\
\hline$<1 / 2$ & $6(46.2)$ & $20(39.2)$ & $1(12.5)$ & 0.274 \\
\hline$\geq 1 / 2$ & $7(53.8)$ & $31(60.8)$ & $7(87.5)$ & \\
\hline \multicolumn{5}{|l|}{$\begin{array}{l}\text { Lymph-vascular space } \\
\text { invasion }\end{array}$} \\
\hline Yes & $1(14.3)$ & $6(18.2)$ & $2(25.0)$ & 0.799 \\
\hline No & $6(85.7)$ & $27(81.8)$ & $6(75.0)$ & \\
\hline \multicolumn{5}{|l|}{$\begin{array}{l}\text { Fallopian tube and/or } \\
\text { ovarian invasion }\end{array}$} \\
\hline Yes & $1(20.0)$ & $6(27.3)$ & $4(66.7)$ & 0.084 \\
\hline No & $4(80.0)$ & $16(72.7)$ & $2(33.3)$ & \\
\hline \multicolumn{5}{|l|}{ Tumoral necrosis } \\
\hline Yes & $0(0.0)$ & $3(10.3)$ & $1(14.3)$ & 0.733 \\
\hline No & $7(100.0)$ & $26(89.7)$ & $6(85.7)$ & \\
\hline
\end{tabular}

$\mathrm{P}<0.05$, statistically significant results; $0.05<\mathrm{P}<0.10$, suggestive results.

endometrial malignancies. Lehner et al identified the mRNA expression of survivin in both normal and malignant endometria (44). In addition, Saitoh et al (46), Konno et al (47) and Lehner et al (44) identified the mRNA expression of survivin in normal endometria. However, Saitoh et al (46) demonstrated that the mRNA expression of survivin in endometrial cancer specimens was significantly higher than in the normal endometria. Ai et al (48), had the same results as Saitoh et al (46). The staining of survivin in the present study showed exclusively nuclear localization. A combination of nuclear and cytoplasmic staining for survivin has been described in the international literature. However, Yilmaz et al (39) did not determine any statistically significant difference between cytoplasmic and nuclear expression.

In the present study, a significant correlation was observed between the sum of staining intensity and scores of survivin immunopositive cells, and patient age $(\mathrm{P}=0.028)$, histological grade $(\mathrm{P}<0.001)$, clinical stage $(\mathrm{P}=0.018)$ and fallopian tube and/or ovarian invasion $(\mathrm{P}=0.039)$. The findings of the present study suggested that survivin may be an indicator of unfavorable outcome in older patients with endometrial carcinomas. In particular, it was found that higher levels of survivin were associated with a higher number of older patients, more cases with higher histological G3 and less cases with G2. In addition, the higher levels of survivin were associated with a larger number of stage II and III patients and a smaller number of stage I patients. However, in previous reports investigating the role of survivin in endometrial cancer, controversial results were obtained. Lambropoulou et al (38), suggested a significant correlation between survivin expression and histological grade, stage, myometrial invasion and survival rates. Lehner et al (44), found a correlation between 
Table IX. Co-expression of survivin and p53 in endometrial carcinoma according to sum of stain intensity and scores of immunopositive cells in relation to clinicopathological parameters.

\begin{tabular}{|c|c|c|c|c|}
\hline Characteristics & $\begin{array}{c}\text { Patients with survivin } \\
\text { and p53 + } \\
\text { expression, } \mathrm{n}(\%)\end{array}$ & $\begin{array}{c}\text { Patients with either } \\
\text { survivin or p53++ } \\
\text { expression, } \mathrm{n}(\%)\end{array}$ & $\begin{array}{c}\text { Patients with survivin } \\
\text { and p53 +++ } \\
\text { expression, n }(\%)\end{array}$ & P-value \\
\hline \multicolumn{5}{|l|}{ Age, years } \\
\hline$<60$ & $2(50.0)$ & $21(35.6)$ & $0(0.0)$ & 0.001 \\
\hline$\geq 60$ & $2(50.0)$ & $38(64.4)$ & $8(100.0)$ & \\
\hline \multicolumn{5}{|l|}{ Histological type } \\
\hline Endometrioid & $4(100.0)$ & $56(94.9)$ & $6(75.0)$ & 0.020 \\
\hline Clear cell and papillary serous & $0(0.0)$ & $3(5.1)$ & $2(25.0)$ & \\
\hline \multicolumn{5}{|l|}{ Clinical stage } \\
\hline I & $3(100.0)$ & $47(88.7)$ & $3(42.9)$ & 0.037 \\
\hline II & $0(0.0)$ & $5(9.4)$ & $3(42.9)$ & \\
\hline III & $0(0.0)$ & $1(1.9)$ & $1(14.3)$ & \\
\hline \multicolumn{5}{|l|}{ Histological differentiation } \\
\hline G1 & $3(75.0)$ & $11(18.6)$ & $1(12.5)$ & 0.001 \\
\hline G2 & $1(25.0)$ & $37(62.7)$ & $2(25.0)$ & \\
\hline G3 & $0(0.0)$ & $11(18.6)$ & $5(62.5)$ & \\
\hline \multicolumn{5}{|l|}{ Myometrial invasion } \\
\hline$<1 / 2$ & $2(50.0)$ & $24(40.7)$ & $0(0.0)$ & 0.100 \\
\hline$\geq 1 / 2$ & $2(50.0)$ & $35(59.3)$ & $8(100.0)$ & \\
\hline \multicolumn{5}{|l|}{ Lymph-vascular space invasion } \\
\hline Yes & $0(0.0)$ & $7(18.9)$ & $2(28.6)$ & 0.842 \\
\hline No & $2(100.0)$ & $30(81.1)$ & $5(71.4)$ & \\
\hline \multicolumn{5}{|c|}{ Fallopian tube and/or ovarian invasion } \\
\hline Yes & $0(0.0)$ & $7(26.9)$ & $3(60.0)$ & 0.026 \\
\hline No & $2(100.0)$ & $19(73.1)$ & $2(40.0)$ & \\
\hline \multicolumn{5}{|l|}{ Tumoral necrosis } \\
\hline Yes & $0(0.0)$ & $4(12.1)$ & $1(16.7)$ & $>0.999$ \\
\hline No & $2(100.0)$ & $29(87.9)$ & $5(83.3)$ & \\
\hline
\end{tabular}

$\mathrm{P}<0.05$, statistically significant results; $0.05<\mathrm{P}<0.10$, suggestive results.

survivin mRNA expression and the histological grade of tumors. Takai et al (16), reported that survivin expression was significantly associated with histological grade, surgical stage, myometrial invasion and survival rate. On the other hand, Ai et al (48) did not observe any association with patient age, histological grade or stage of endometrial carcinomas. Pallares et al (36), had similar results with Ai et al (48). In addition, Erkanli et al (41) found no correlation between survivin and the classic prognostic factors for endometrial carcinomas, such as histological grade, stage and myometrial invasion or survival in patients with endometrial carcinomas. Their results were supported by Yilmaz et al (39) as they did not find any association between survivin expression and the clinical prognostic factors including lymphovascular space involvement and extrauterine spread of disease or survival. Aksoy et al (42), found no statistical association between survival and prognostic factors such as histological grade, stage, or cytoplasmic and nuclear expression of survivin in endometrial carcinomas. All these differences with regard to the prognostic role of survivin in endometrial carcinoma may be due to different concomitant genetic alterations and different molecular pathways taking place during endometrial carcinogenesis and metastatic expansion. It is possible that the plethora of different concomitant genetic interactions results in a different biological behavior of endometrial carcinomas. In fact, it has been indicated that poor prognosis was associated with concomitant PI3K/AKT and p53 alterations in endometrial carcinomas (49). Nout et al (50), reported that the concomitant activation of p53 with microsatellite instability was a strong genetic prognostic factor for disease-free survival in endometrial carcinomas. It has also been found that the PTEN-positive and phosphorylated-AKT-negative expression is a good predictor of survival in patients with advanced endometrial carcinomas (51). In addition to these findings, survivin appears to demonstrate multi-functional action that promotes proliferation, angiogenesis and metastatic spread on top of inhibiting apoptosis (52-54). In order to determine the exact prognostic significance of the expression of survivin 

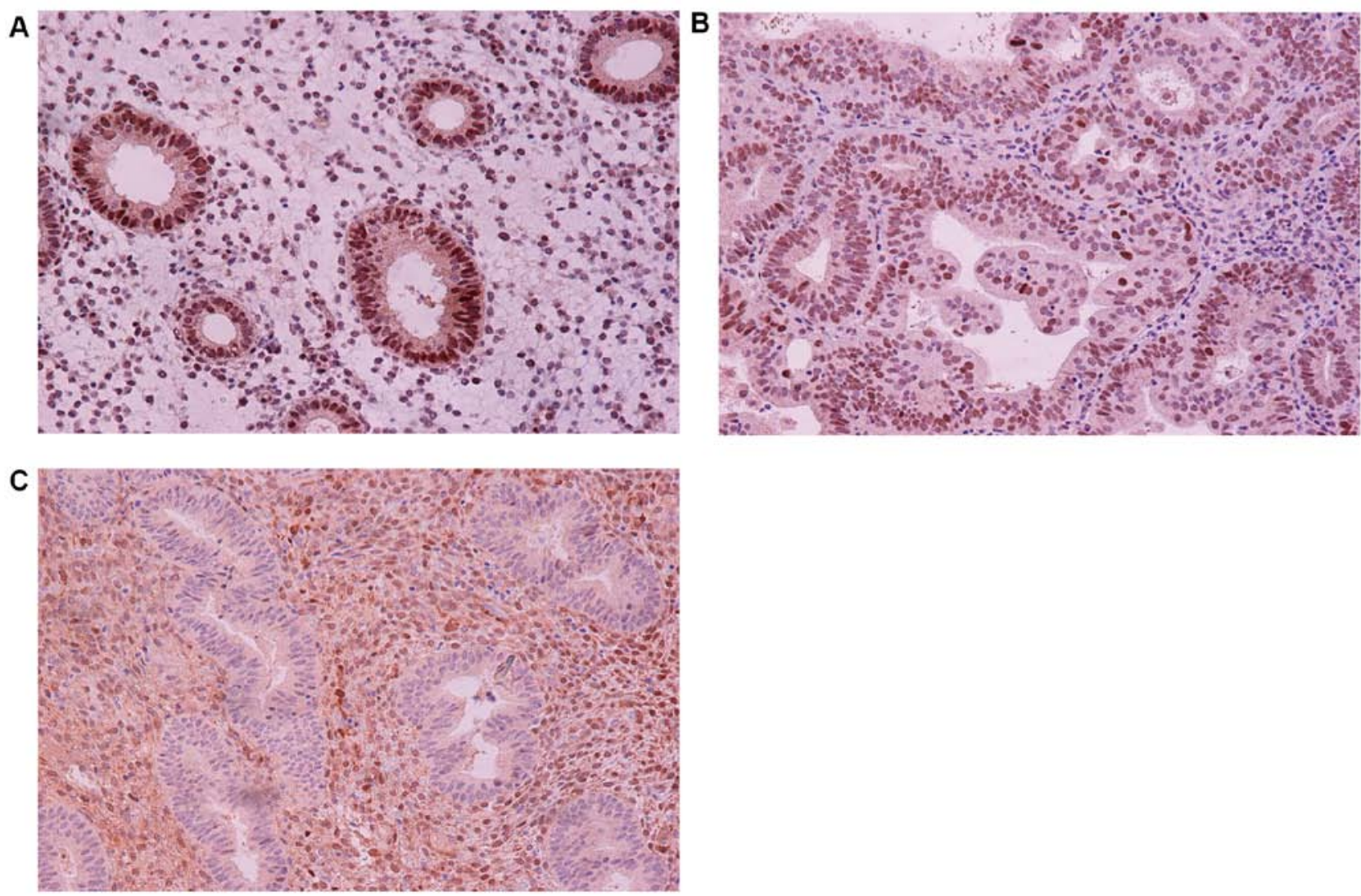

Figure 8. Immunohistochemical p53 expression and absence of p53 expression in normal and hyperplastic endometria. (A) Moderate positivity of p53 expression in the proliferative phase of a normal endometrium. Original magnification, x200. (B) Strong positivity of p53 expression in complex endometrial hyperplasia. Original magnification, x200. (C) Absence of p53 expression in the proliferative phase of a normal endometrium. Original magnification, x200.
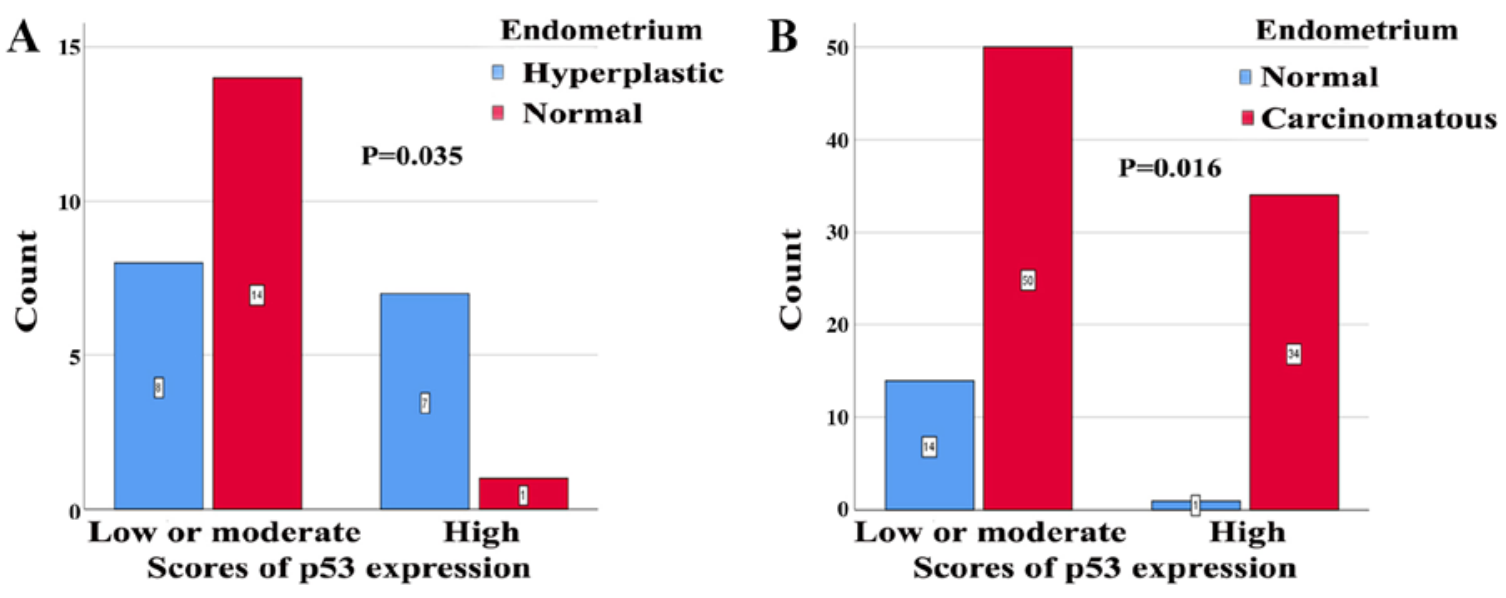

Figure 9. p53 immunostaining scores in normal, hyperplastic and carcinomatous endometria. (A) More patients with endometrial hyperplasia had high p53 positive cell scores, as compared with those with normal endometria $(\mathrm{P}=0.035)$. (B) More patients with endometrial carcinoma showed positive p53 expression, as compared with those with normal endometria $(\mathrm{P}=0.016)$.

in endometrial carcinoma, a deeper understanding of the interaction of survivin with other genetic alterations that take place during tumor development, progression and metastatic process was required. It appears that molecular interaction between survivin and $\mathrm{X}$-linked inhibitor of apoptosis protein stimulates tumor cell invasion and promotes metastasis (55). An association between the co-expression of survivin and the vascular endothelial growth factor-C (VEGF-C) in lymph node metastasis has been identified in breast (56), gastric (57) and papillary thyroid carcinomas (58). All these findings indicated that the regulated expression of VEGF-C by survivin is essential for the invasion and lymphatic metastasis of these tumors (58). With regards to the relationship between survivin and p53 at the molecular level, the following are known so far: Functional p53-binding sites have been identified withing the BIRC5 gene promoter, suggesting the possible involvement of p53 in the direct repression of BIRC5 gene promoter activity $(59,60)$. There have been indications that wild-type, 
A
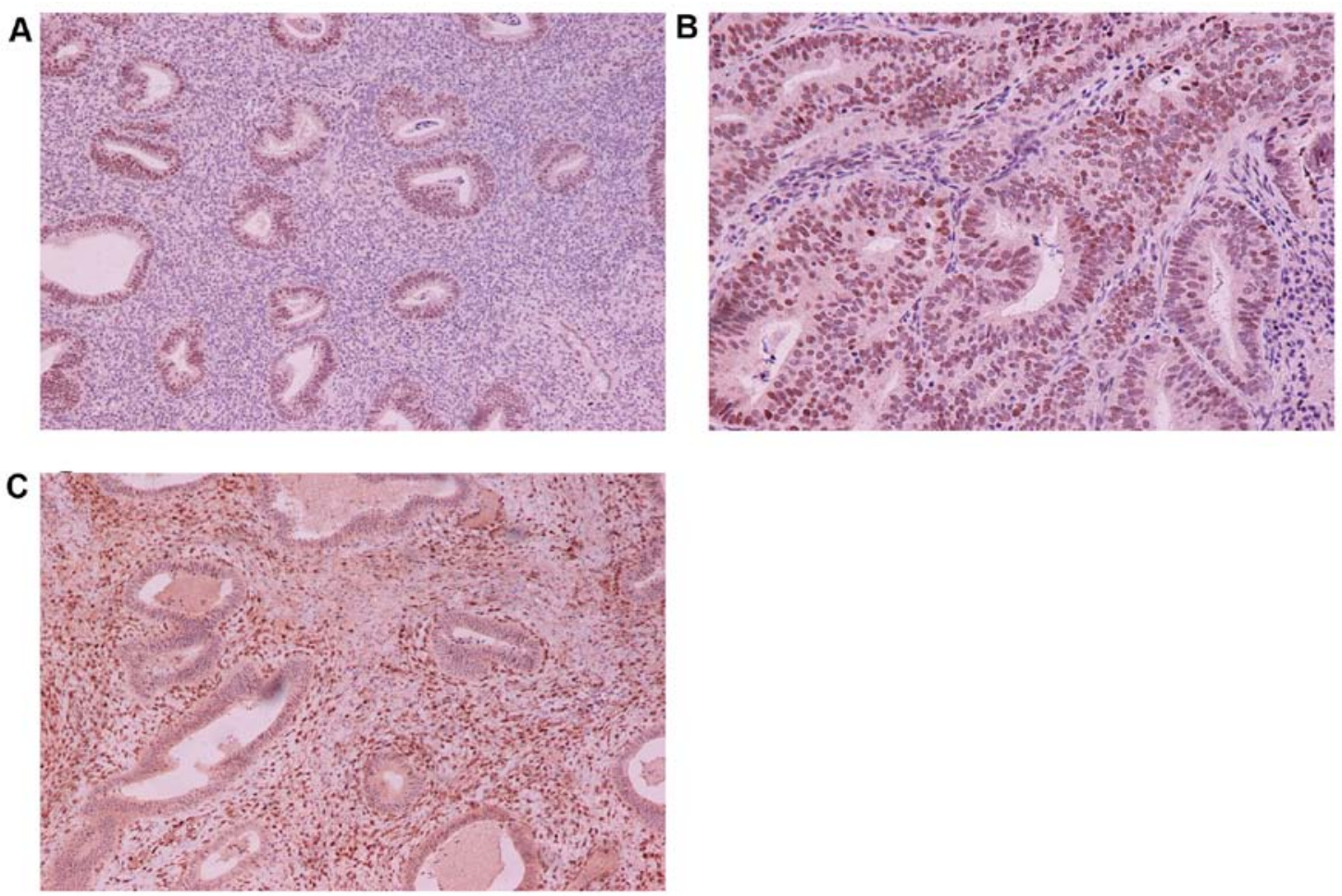

Figure 10. Demonstration of immunohistochemical PTEN expression and absence of PTEN expression in normal and hyperplastic endometria. (A) Moderate positivity of PTEN expression in the proliferative phase of a normal endometrium. Original magnification, x100. (B) Moderate positivity of PTEN expression in complex endometrial hyperplasia. Original magnification, $x 200$. (C) Absence of PTEN expression in the proliferative phase of a normal endometrium. Original magnification, $x 100$. PTEN, phosphatase and tensin homolog.

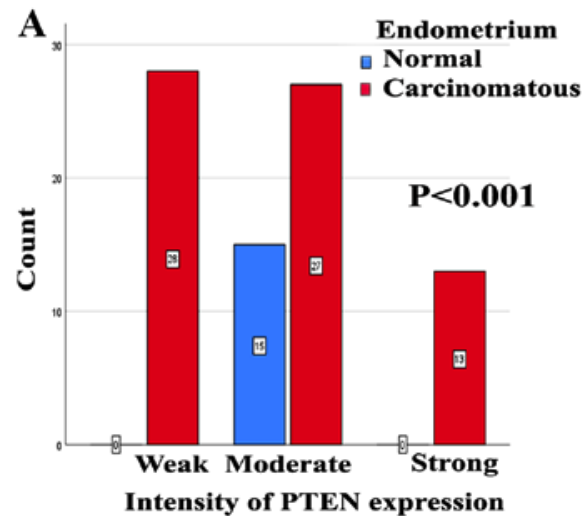

C

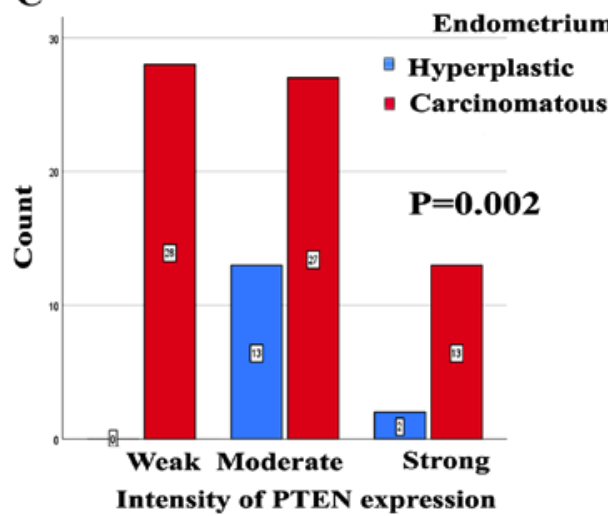

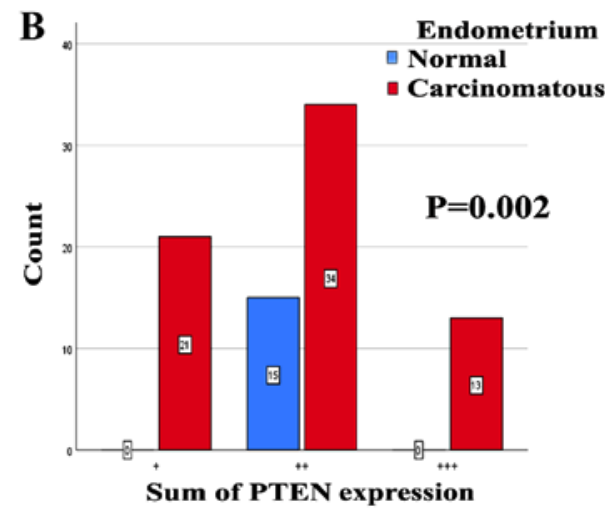

D

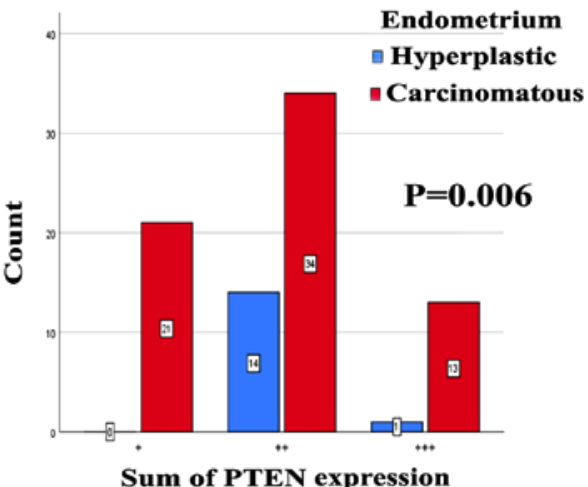

Figure 11. Immunohistochemical PTEN expression in normal, hyperplastic and carcinomatous endometria. (A) A statistically significant difference in the staining intensity of PTEN immunopositive cells was identified between normal endometria and endometrial carcinomas $(\mathrm{P}<0.001)$. A statistically significant association was identified in (B) the sum of staining intensity and scores of PTEN immunopositive cells ( $\mathrm{P}=0.002),(\mathrm{C})$ intensity of $\mathrm{PTEN}$ expression ( $\mathrm{P}=0.002)$ and (D) sum of staining intensity and scores of PTEN immunopositive cells $(\mathrm{P}=0.006)$ between endometrial hyperplasias and endometrial carcinomas. PTEN, phosphatase and tensin homolog. 

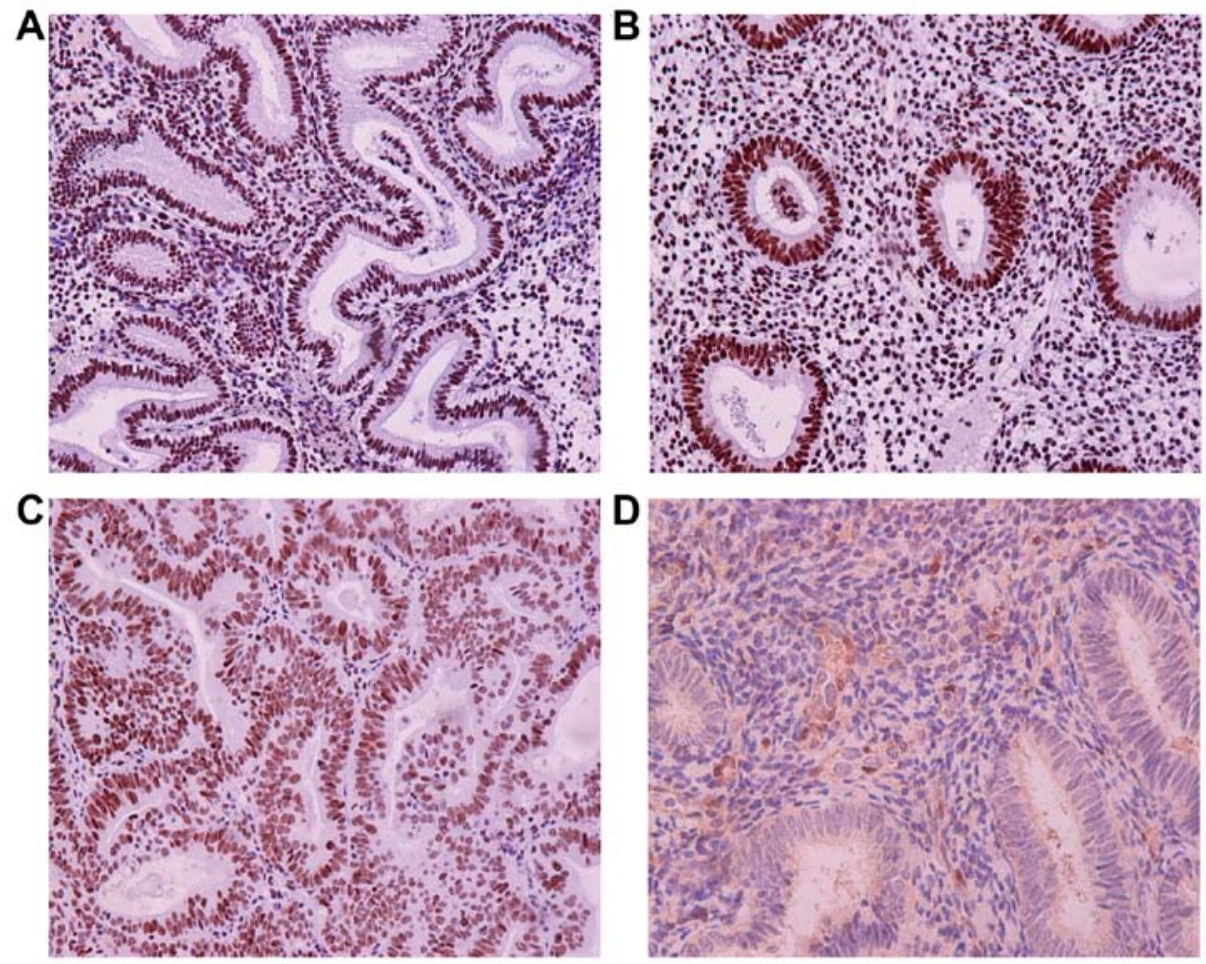

Figure 12. Demonstration of immunohistochemical survivin expression and absence of survivin expression in normal and hyperplastic endometria. Strong survivin positivity in (A) a normal secretory endometrium (original magnification, x200), (B) a normal proliferative endometrium (original magnification, $\mathrm{x} 200$ ) and (C) complex endometrial hyperplasia (original magnification, $\mathrm{x} 200$ ). (D) Negative immunohistochemical survivin staining in a normal proliferative endometrium. Original magnification, $\mathrm{x} 400$.
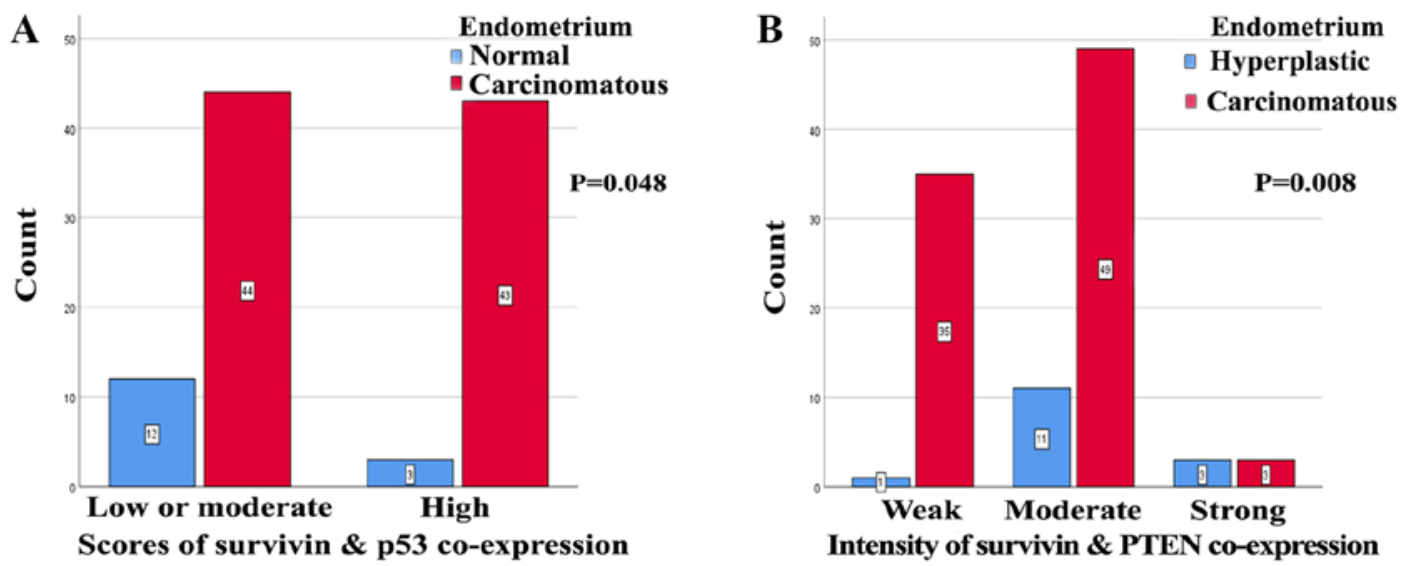

Figure 13. Findings of immunohistochemical survivin expression in normal, hyperplastic and carcinomatous endometria in the case of concomitant p53 or PTEN immunohistochemical positivity. (A) Proportion of survivin immunopositive cells (scores) with concomitant p53 expression. A statistically significant difference in the expression of survivin was observed between normal endometria and endometrial carcinomas ( $\mathrm{P}=0.048)$. (B) Intensity of survivin expression with concomitant PTEN expression. A statistically significant difference in the expression of survivin was observed between endometrial hyperplasias and endometrial carcinomas $(\mathrm{P}=0.008)$. $\mathrm{PTEN}$, phosphatase and tensin homolog.

but not mutated p53 represses BIRC5 expression upon DNA damage at the transcription level, and regulates normal cell cycle and apoptosis (60-62). In addition, p53 represses BIRC5 gene promoter activity by counteracting the BIRC5 promoter through the binding of Sp1 factor and hypoxia inducing factor $(63,64)$. It has been found that, in normal endometria, the BIRC5 gene promoter is completely unmethylated, while in endometrial cancers the hypermethylation of the BIRC5 gene promoter blocks the binding of p53 to its promoter region and causes the elevated expression of the survivin protein (65). On the other hand, survivin overexpression mediates the p53-dependent apoptotic pathway through the mouse double minute 2 homolog (MDM2) oncoprotein. In fact, it has been shown that the overexpression of survivin causes the promotion of p53 degradation through the inhibition of MDM2 cleavage (66). With regards to the association between survivin and PTEN at the molecular level, the survivin gene is negatively regulated by PTEN (67). It has been reported that the acute silencing of the survivin gene is essential for endogenous PTEN-mediated tumor suppres- 
sion through the binding of Forkhead Box O1 (FOXO1) and FOXO2 factors to the proximal survivin promoter in several types of cancers $(26,68,69)$.

In the present study, we investigated the effects of immunohistochemical PTEN and p53 expression on the expression of survivin in endometrial carcinomas. In our previous study we investigated the distribution of tumor suppressor genes p53 and PTEN in primary endometrial carcinoma specimens acquired from Greek patients and analyzed the clinical significance of the combination of p53 and PTEN expression (43). We believe that the present findings are interesting, since the clinical significance of the interplay between the expression of the tumor suppressor genes PTEN and p53, and survivin in endometrial carcinomas remained unknown so far. In our previous study the levels of $\mathrm{p} 53$ and PTEN co-expression were found to be correlated with patient age $(\mathrm{P}=0.08)$ and histological differentiation $(\mathrm{P}=0.028)$, according to the scores of immunopositive cells. We therefore suggested that the concomitant expression of p53 and PTEN may play a role in the development of high-grade endometrial carcinomas in older patients (43). In addition, these findings suggested the involvement of different molecular pathways in the development of low- and high-grade endometrial carcinomas (43). In the present study, a negative tendency was identified between the scores of survivin and PTEN expression $(\mathrm{P}=0.062, \rho=-0.238)$. It appears that cases with high scores of survivin immunoexpression tended to have decreased scores of PTEN immunostaining, and vice versa. This finding is very interesting, as PTEN and survivin are two inverse factors of apoptosis (28). This finding was strengthened by the study of Pallares et al (36), in which they identified a statistically significant negative correlation between survivin and PTEN expression. PTEN and survivin appear to act in opposite ways from each other in endometrial carcinoma, and PTEN modulates the survivin level via the PI3K/AKT pathway $(28,36)$. However, Erkanli et al (37) did not report such correlation probably due to i) the low number of studied patients with endometrial carcinoma and ii) the fact that no patients with papillary serous or clear cell adenocarcinomas were included in the study. Therefore, further research that includes a larger number of patients is required in order to clarify the exact role of the interaction and relationship between the expression of survivin and that of PTEN in endometrial carcinoma. This could lead to the development of novel target gene therapies for the effective treatment of endometrial carcinoma. In the present study, a statistically significant correlation was identified between the sum of staining intensity and scores of survivin and PTEN immunopositivity and histological type in endometrial adenocarcinomas $(\mathrm{P}=0.020)$. In fact, it was found that moderate levels of survivin and PTEN co-expression were associated with a higher frequency of endometrioid histological types, while the high levels of concomitant survivin and PTEN expression were associated with a lower frequency of endometrioid histological types. In cases of concomitant survivin and PTEN expression, a statistically significant correlation was observed according to the staining intensity and histologic grade $(\mathrm{P}=0.023)$, presence of lymph-vascular space invasion $(\mathrm{P}=0.007)$ and fallopian tube and/or ovarian invasion $(\mathrm{P}=0.031)$. These findings suggested that the co-expression of and interaction between survivin and PTEN may play a role in the development of more aggressive endometrial carcinomas. In the present study, in cases with concomitant
PTEN and survivin, and according to the intensity of immunochemical positivity, a statistically significant difference in the expression of survivin was identified between endometrial hyperplasias and endometrial carcinomas $(\mathrm{P}=0.008)$. In addition, the sum of survivin staining scores and intensity in cases with concurrent PTEN positive staining showed a statistically significance in the expression of survivin between endometrial hyperplasias and endometrial carcinomas $(\mathrm{P}=0.016)$. Therefore, the present findings clearly indicated the interaction between survivin and PTEN during endometrial carcinogenesis.

Survivin and p53 co-expression and their association with the clinical behavior and histological types of endometrial carcinomas were investigated in the present study, due to the limited related data in the literature so far. A statistically significantly positive correlation between survivin and p53 concurrent expression was identified based on staining intensity $(\mathrm{P}=0.001, \rho=0.372)$ or the sum of staining intensity and scores $(\mathrm{P}=0.008, \rho=0.300)$. These findings suggested that these proteins are strongly positively correlated and may share a common molecular pathway through which they regulate each other's action and promote endometrial carcinogenesis. Herein, a significant correlation was found between the sum staining intensity and scores of survivin and p53 immunopositivity and age of patients $(\mathrm{P}=0.001)$, histological type $(\mathrm{P}=0.020)$, clinical stage $(\mathrm{P}=0.037)$, histological differentiation $(\mathrm{P}=0.001)$ and presence of fallopian tube and/or ovarian invasion $(\mathrm{P}=0.026)$. These results showed the synergic action of survivin and 553 and indicated their prognostic value for endometrial cancer. A concomitant expression of survivin and p53 seems to favor the growth of more aggressive endometrial carcinomas in older patients. The concomitant expression of these markers could have a prognostic significance. Survivin and p53 could be important targets for therapeutic interventions in new target gene therapies for endometrial malignancies. A statistically significant difference in the scores of immunohistochemical survivin staining was observed between normal endometria and endometrial carcinomas $(\mathrm{P}=0.048)$. The present findings suggested the importance of concurrent survivin and p53 expression for the development of endometrial carcinomas.

In conclusion, the expression of survivin in specific circumstances appears to depend on different concomitant genetic alterations and the different combinations of molecular pathways in endometrial carcinogenesis. This study showed a negative tendency for correlation between the concurrent immunopositive survivin and PTEN cell scores, and suggested their pivotal role in the development of more aggressive tumors in such circumstances. Moreover, the survivin and p53 proteins may share a common molecular pathway, and their combined evaluation may implicate them in the prediction of tumor behavior and prognosis.

\section{Acknowledgements}

The present study was part of a thesis for a Doctor of Philosophy (Ph.D.) in Obstetrics and Gynecology, Medical School, Kapodistrian University of Athens, Greece for AS.

\section{Funding}

No funding was received. 


\section{Availability of data and materials}

The datasets used and/or analyzed during the present study are available from the corresponding author on reasonable request.

\section{Authors' contributions}

All authors were responsible for the conception and design of the present study. TV and AT were responsible for the provision of the study materials. TV, AT, VKV and FNV were responsible for the collection and assembly of the data. AS, MV, TV, VKV, FNV, AT, AN, NK and ACL performed the data analysis and interpretation. AS, MV, TV, VKV, FNV, AT, $\mathrm{AN}, \mathrm{NK}$ and ACL contributed to writing of the manuscript. All authors read and approved the final manuscript.

\section{Ethics approval and consent to participate}

The present study was approved by the Ethics Committee of Medical School of Kapodistrian University of Athens, Greece. Written informed consent was obtained from all patients for the use of their tumor specimens and their data in analysis.

\section{Patient consent for publication}

All patients included in the present study provided consent for their data to be used in this publication at the time of data collection.

\section{Competing interests}

The authors declare that they have no competing interests.

\section{References}

1. Jemal A, Siegel R, Xu J and Ward E: Cancer statistics, 2010. CA Cancer J Clin 60: 277-300, 2010.

2. Sadlecki P, Bodnar M, Grabiec M, Marszalek A, Walentowicz P, Sokup A, Zegarska J and Walentowicz-Sadlecka M: The role of Hypoxia-inducible factor $1 \alpha$, glucose transporter-1 (GLUT-1) and carbon anhydrase IX in endometrial cancer patients. Biomed Res Int 2014: 616850, 2014.

3. Daniilidou K, Frangou-Plemenou M, Grammatikakis J, Grigoriou O, Vitoratos N and Kondi-Pafiti A: Prognostic significance and diagnostic value of PTEN and p53 expression in endometrial carcinoma. A retrospective clinicopathological and immunohistochemical study. J BUON 18: 195-201, 2013.

4. Talhouk A and McAlpine JN: New classification of endometrial cancers: The development and potential applications of genomic-based classification in research and clinical care. Gynecol Oncol Res Pract 3: 14, 2016.

5. Taoussi N, Alghamdi A, Futyma $K$ and Rechberger $T$ : Biological markers with potential clinical value in endometrial cancer-review of the literature. Ginekol Pol 88: 331-336, 2017.

6. Mancebo G, Sole-Sedeno JM, Pino O, Miralpeix E, Mojal S, Garrigos L, Lloveras B, Navarro P, Gibert J, Lorenzo M, et al: Prognostic impact of CD133 expression in endometrial cancer patients. Sci Rep 7: 7687, 2017.

7. Zhang HM, Fan TT, Li W and Li XX: Expressions and significances of TTF-1 and PTEN in early endometrial cancer. Eur Rev Med Pharmacol 21 (3 Suppl): S20-S26, 2017.

8. Hashmi AA, Hussain ZF, Qadri A, Irfan M, Ramzan S, Faridi N, Khan A and Edhi MM: Androgen receptor expression in endometrial carcinoma and its correlation with clinicopathologic features. BMC Res Notes 11: 289, 2018.

9. Bakkum-Gamez JN, Gonzalez-Bosquet J, Laack NN, Mariani A and Dowdy SC: Current issues in the management of endometrial cancer. Mayo Clin Proc 83: 97-112, 2008.
10. Ambrosini G, Adida C and Altieri DC: A novel anti-apoptosis gene, survivin, expressed in cancer and lymphoma. Nat Med 3: 917-921, 1997.

11. Rudin CM and Thompson CB: Apoptosis and disease: Regulation and clinical relevance of programmed cell death. Annu Rev Med 48: 267-281, 1997.

12. LaCasse EC, Baird S, Korneluk RG and MacKenzie AE: The inhibitors of apoptosis (IAPs) and their emerging role in cancer. Oncology 17: 3247-3259, 1998.

13. Tamm I, Wang Y, Sausville E, Scudiero DA, Vigna N, Oltersdorf T and Reed JC: IAP-family protein survivin inhibits caspase activity and apoptosis induced by Fas (CD95), Bax, caspases, and anticancer drugs. Cancer Res 58: 5315-5320, 1998.

14. Altieri DC: Survivin, cancer networks and path-directed drug discovery. Nat Rev Cancer 8: 61-70, 2008.

15. Cohen C, Lohmann CM, Cotsonis G,Lawson D and Santoianni R: Survivin expression in ovarian carcinoma: Correlation with apoptotic markers and prognosis. Mod Pathol 16: 574-583, 2003.

16. Takai N, Miyazaki T, Nishida M, Nasu K and Miyakawa I: Survivin expression correlates with clinical stage, histological grade, invasive behavior and survival rate in endometrial carcinoma. Cancer Lett 184: 105-116, 2002.

17. Tran J, Master Z, Yu JL, Rak J, Dumont DJ and Kerbel RS: A role for survivin in chemoresistance of endothelial cells mediated by VEGF. Proc Natl Acad Sci USA 99: 4349-4354, 2002.

18. Altieri DC: Survivin, versatile modulation of cell division and apoptosis in cancer. Oncogene 22: 8581-8589, 2003.

19. Altieri DC: Survivin and apoptosis control. Adv Cancer Res 88: 31-52, 2003.

20. Mita AC, Mita MM, Nawrocki ST and Giles FJ: Survivin: Key regular of mitosis and apoptosis and novel target for cancer therapeutics. Clin Cancer Res 14: 5000-5005, 2008.

21. Li F, Ambrosini G, Chu EY, Plescia J, Tognin S, Marchisio PC and Altieri DC: Control of apoptosis and mitotic spindle checkpoing by survivin. Nature 396: 580-584, 1998.

22. Mahotka C, Wenzel M, Springer E, Gabbert HE and Gerharz CD: Survivin-deltaEx3 and survivin-2B: Two novel splice variants of the apoptosis inhibitor survivin with different antiapoptotic properties. Cancer Res 59: 6097-6102, 1999.

23. Zhang M, Yang J and Li F: Transcriptional and post-transcriptional controls of survivin in cancer cells: Novel approaches for cancer treatment. J Exp Clin Cancer Res 25: 391-402, 2006.

24. Dohi T, Beltrami E, Wall NR, Plescia J and Alteiri DC: Mitochondrial survivin inhibits apoptosis and promotes tumorigenesis. J Clin Invest 114: 1117-1127, 2004.

25. Sui L, Dong Y, Ohno M, Watanabe Y, Sugimoto K and Tokuda M: Survivin expression and its correlation with cell proliferation and prognosis in epithelial ovarian tumors. Int J Oncol 21: 315-120, 2002.

26. Guha M. Plescia J, Leav I, Li J, Languino LR and Altieri DC: Endogenous tumor suppression mediated by PTEN involves survivin gene silencing. Cancer Res 69: 4954-4958, 2009.

27. Kim S, Kang J, Qiao J, Thomas RP, Evers BM and Chung DH: Phosphatidylinositol 3-kinase inhibition down-regulates survivin and facilitates TRAIL-mediated apoptosis in neuroblastomas. J Padiatr Surg 39: 516-521, 2004.

28. Sui L, Dong, Watanabe Y, Yamaguchi F, Sugimoto K and Tokuda M: Alteration and clinical relevance of PTEN expression and its correlation with survivin expression in epithelial ovarian tumors. Oncol Rep 15: 773-778, 2006.

29. Grossman D, Kim PJ, Blanc-Brude OP, Brash DE, Tognin S, Marchisio PC and Altieri DC: Transgenic expression of survivin in keratinocytes counteracts UVB-induced apoptosis and cooperates with loss of p53. J Clin Invest 108: 991-999, 2001.

30. Hoffman WH, Biade S, Zilfou JT, Chen J and Murphy M: Trascriptional repression of the anti-apoptotic survivin gene by wild type p53. J Biol Chem 277: 3247-3257, 2002.

31. Mirza A, McGuirk M, Hockenberry TN, Wu Q, Ashar H, Black S, Wen SF, Wang L, Kirschmeier P, Bishop WR, et al: Human survivin is negatively regulated by wild-type p53 and participates in p53-dependent apoptotic pathway. Oncogene 21: 2613-2622, 2002.

32. Kannangai R, Wang J, Liu QZ, Sahin F and Torbenson M: Survivin overexpression in hepatocellular carcinoma is associated with p53 dysregulation. Int J Gastrointest Cancer 35: 53-60, 2005.

33. Felisiak-Golabek A, Rembiszewska A, Rzepecka IK Szafron L, Madry R, Murawska M, Napiorkowski T, Sobiczewski P, Osuch B and Kupryjanczyk J; PolishOvarian Cancer Study Group (POCSG): Nuclear survivin expression is a positive prognostic factor in taxane-platinum-treated ovarian cancer patients. J Ovarian Res 4: 20, 2011 
34. Gąsowska-Bodnar A, Bodnar L, Dabek A, Cichowicz M, Jerzak M, Cierniak S, Kozłowski W and Baranowski W: Survivin expression as a prognostic factor in patients with epithelial ovarian cancer or primary peritoneal cancer treated with neoadjuvant chemotherapy. Int J Gynecol Cancer 24: 687-696, 2014.

35. Gonzalez S, Aubert S, Kerdraon O, Haddad O, Fantoni JC Bisere $\mathbf{J}$ and Lorey X: Prognostic value of combined p53 and survivin in pT1G3 urothelial carcinoma of the bladder. Am J Clin Pathol 129: 232-237, 2008.

36. Pallares J, Martínez-Guitarte JL, Dolcet X, Llobet D, Rue M, Palacios J, Prat J and Matias-Guiu X: Survivin expression in endometrial carcinoma: A tissue microarray study with correlation with PTEN and STAT-3. Int J Gynecol Pathol 24: 247-253, 2005.

37. Erkanli S, Kayaselcuk F, Kuscu E, Bagis T, Bolat F, Haberal A and Demirhan B: Expression of survivin, PTEN and p27 in normal, hyperplastic, and carcinomatous endometrium. Int J Gynecol Cancer 16: 1412-1418, 2006.

38. Lambropoulou M, Papadopoulos N, Tripsianis G, Alexiadis G, Pagonopoulou O, Kiziridou A, Liberis V, Kakolyris S and Chatzaki E: Co-expression of survivin, c-erbB2, and cyclooxygenase-2 (COX-2): Prognostic value and survival of endometrial cancer patients. J Cancer Res Clin Oncol 136: 427-435, 2010

39. Yilmaz E, Koyuncuoglu M, Görken IB, Okyay E, Saatli B, Ulukus EC and Saygili U: Expression of matrix metalloproteinase-2 and survivin in endometrioid and nonendometrioid endometrial cancers and clinicopathologic significance. J Gynecol Oncol 22: 89-96, 2011.

40. Brunner A, Riss P, Heinze G and Brustmann H: pHH3 and survivin are co-expressed in high-risk endometrial cancer and are prognostic relevant. Br J Cancer 107: 84-90, 2012.

41. Erkanli S, Bolat F, Kayaselcuk F, Demirhan B and Kuscu E: COX-2 and survivin are overexpressed and positively correlated in endometrial carcinoma. Gynecol Oncol 104: 320-325, 2007.

42. Aksoy RT, Turan AT, Boran N, Tokmak A, Isikdogan BZ, Tulunay HG and Dogan M: Lack of relation of survivin gene expression with survival and surgical prognostic factors in endometrial carcinoma patients. Asian Pac J Cancer Prev 15 6905-6910, 2014

43. Stavropoulos A, Varras M, Vasilakaki T, Varra VK, Tsavari A, Varra FN, Nonni A, Kavantzas N and Lazaris AC: Expression of p53 and PTEN in human primary endometrial carcinomas: Clinicopathological and immunohistochemical analysis and study of their concomitant expression. Oncol Lett 17: 4575-4589, 2019.

44. Lehner R, Enomoto T, McGregor JA, Shroyer L, Haugen BR, Pugazhenthi U and Shroyer KR: Correlation of survivin mRNA detection with histologic diagnosis in normal endometrium and endometrial carcinoma. Acta Obstet Gynecol Scand 81: 162-167, 2002.

45. Chuwa AH, Sone K, Oda K, Ikeda Y, Fukuda T, Wada-Hiraike O, Inaba K, Makii C, Takeuchi M, Oki S, et al: Significance of survivin as a prognostic factor and a therapeutic target in endometrial cancer. Gynecol Oncol 141: 564-569, 2016.

46. Saitoh Y, Yaginuma Y and Ishikawa M: Analysis of Bcl-2, Bax and survivin genes in uterine cancer. Int J Oncol 15: 137-141, 1999.

47. Konno R, Yamakawa H, Utsunomiya H, Ito K, Sato $\mathrm{S}$ and Yajima A: Expression of survivin and Bcl-2 in normal human endometrium. Mol Hum Reprod 6: 529-534, 2000.

48. Ai Z, Yin L, Zhou X, Zhu Y, Zhu D, Yu Y and Feng Y: Inhibition of survivin reduces cell proliferation and induces apoptosis in human endometrial cancer. Cancer 107: 746-756, 2006.

49. Catasus L, Gallardo A, Cuatrecasas M and Prat J: Concomitant $\mathrm{PI} 3 \mathrm{~K}-\mathrm{AKT}$ and p53 alterations in endometrial carcinomas are associated with poor prognosis. Mod Pathol 22: 522-529, 2009.
50. Nout RA, Bosse T, Creutzberg CL, Jürgenliemk-Schulz IM, Jobsen JJ, Lutgens LC, van der Steen-Banasik EM, van Eijk R, Ter Haar NT and Smit VT: Improved risk assessment of endometrial cancer by combined analysis of MSI, PI3K-AKT, Wnt/3-caterin and P53 pathway activation. Gynecol Oncol 126: 466-473, 2012.

51. Uegaki K, Kanamori Y, Kigawa J, Kawaguchi W, Kaneko R, Naniwa J, Takahashi M, Shimada M, Oishi T, Itamochi H and Terakawa N: PTEN-positive and phosphorylated-Akt-negative expression is a predictor of survival for patients with advanced endometrial carcinoma. Oncol Rep 14: 389-392, 2005.

52. Deveraux QL and Reed JC: IAP family proteins-suppressors of apoptosis. Genes Dev 13: 239-252, 1999.

53. Sanhueza C, Wehinger S, Castillo Bennett J, Valenzuela $M$, Owen GI and Quest AF: The twisted survivin connection to angiogenesis. Mol Cancer 14: 198, 2015.

54. Yan YL and Li XM: The IAP family: Endogenous caspase inhibitors with multiple biological activities. Cell Res 10: 169-177, 2000.

55. Mehrotra S, Languino LR, Raskett CM, Mercurio AM, Dohi T and Altieri DC: IAP regulation of metastasis. Cancer Cell 17: 53-64, 2010.

56. Cai X, Ma S, Gu M, Zu C, Qu W and Zheng X: Survivin regulates the expression of VEGF-C in lymphatic metastasis of breast cancer. Diagn Pathol 7: 52, 2012.

57. Zhang J, Zhu Z, Sun Z, Sun X, Wang Z and Xu H: Survivin gene expression increases gastric cancer cell hymphatic metastasis by upregulating vascular endothelial growth factor-C expression levels. Mol Med Red 9: 600-606, 2014.

58. Selemtjev S, Savin S, Paunovic I, Tatic S and Cvejic D: Concomitant high expression of survivin and vascular endothelial growth factor-C is strong associated with metastatic status of lymph nodes in papillary thyroid carcinoma. J Cancer Res Ther 14 (Suppl): S114-S119, 2018.

59. Nakano J, Huang CL, Liu D, Ueno M, Sumitomo $S$ and Yokomise H: Survivin gene expression is negatively regulated by the p53 tumor suppressor gene in non-small cell lung cancer. Int J Oncol 27: 1215-1221, 2005.

60. Lyu H, Huang J, He Z and Liu B: Epigenetic mechanist of survivin dysregulation in human cancer. Sci China Life Sci 61: 808-814, 2018.

61. Chen X, Duan N, Zhang C and Zhang W: Survivin and tumorigenesis: Molecular mechanisms and therapeutic strategies. J Cancer 7: 314-323, 2016

62. Pei SG, Wang JX, Wang XL, Zhang QJ and Zhang H: Correlation of survivin, p53 and Ki-67 in laryngeal cancer Hep-2 cell proliferation and invasion. Asian Pac J Trop Med 8: 636-642, 2015.

63. Estève PO, Chin HG and Pradhan S: Molecular mechanisms of transactivation and doxorubicin-mediated repression of survivin gene in cancer cells. J Biol Chem 282: 2615-2625, 2007.

64. Smallwood A, Estève PO, Pradhan S and Carey M: Functional cooperation between HP1 and DNMT1 mediates gene silencing. Genes Dev 21: 1169-1178, 2007.

65. Nabilsi NH, Broaddus RR and Loose DS: DNA methylation inhibits p53-mediated survivin repression. Oncogene 28: 2046-2050, 2009.

66. Wang Z, Fukuda S and Pelus LM: Survivin regulates the p53 tumor suppressor gene family. Oncogene 23: 8146-8153, 2004.

67. Guha M, Altieri DC: Survivin as a global target of intrinsic tumor suppression networks. Cell Cycle 8: 2708-2710, 2009.

68. Calnan DR and Brunet A: The FoxO code. Oncogene 27: 2276-2288, 2008.

69. Accili D and Arden KC: FoxOs at the crossroads of cellular metabolism, differentiation, and transformation. Cell 117: 421-426, 2004

This work is licensed under a Creative Commons Attribution-NonCommercial-NoDerivatives 4.0 International (CC BY-NC-ND 4.0) License. 